\title{
Photoinduced energy-transfer in covalently and non-covalently linked supramolecular arrays of metal polypyridyl complexes
}

\author{
Michael D. Ward \\ School of Chemistry, University of Bristol, Cantock's Close, Bristol BS8 1TS, UK
}

\begin{abstract}
Photoinduced energy-transfer has been studied between the component parts of two types of multichromophoric array. In the first type the components (metal polypyridyl complexes) are covalently linked by using the bridging ligand $2,2^{\prime}: 3^{\prime}, 2^{\prime \prime}: 6^{\prime \prime}, 2^{\prime \prime \prime}$-quaterpyridine, which has two inequivalent bipyridyl chelating sites in close proximity. Structural, redox and photophysical studies of the complexes based on this ligand show how the properties of each metal fragment vary between the two inequivalent binding sites, and show also how efficient inter-component energy transfer can occur between components, with an example of the antenna effect being demonstrated by energy transfer from three peripheral $\left\{\mathrm{Re}(\right.$ bipy $\left.)(\mathrm{CO})_{3} \mathrm{Cl}\right\}$ fragments to one central $\left\{\mathrm{Ru}(\mathrm{bipy})_{3}\right\}^{2+}$ fragment. In the second type of supramolecular array, the mononuclear complex component parts are held together by hydrogen-bonding between peripheral adenine, thymine, cytosine or guanine nucleobase groups. Thus a $\left\{\mathrm{Ru}(\mathrm{bipy})_{3}\right\}^{2+}$ derivative with a pendant cytosine group strongly associates in $\mathrm{CH}_{2} \mathrm{Cl}_{2}$ solution with an $\left\{\mathrm{Os}(\text { bipy })_{3}\right\}^{2+}$ complex bearing a pendant guanine group, by Watson-Crick base-pair formation $\left(\mathrm{K}_{\mathrm{a}} \approx 5000 \mathrm{M}^{-1}\right)$, and $\mathrm{Ru} \rightarrow$ Os photoinduced energy-transfer can occur across the triple hydrogen-bonded bridge.
\end{abstract}

\section{INTRODUCTION}

The study of photoinduced energy or electron transfer between a chromophore and a quencher in polynuclear complexes, one of the most intensively studied areas in current inorganic chemistry, is of interest for two distinct reasons. The first is the desire to understand and mimic the naturally occurring process of photosynthesis, which relies on a complex series of energytransfer and electron-transfer processes to harness the energy of sunlight by converting $\mathrm{CO}_{2}$ and water to sugars. The second is to exploit these processes in artificial systems, in ways that have not developed naturally, for applications as diverse as molecular sensing, photocatalysis, and molecular electronics.

To prepare chromophore/quencher assemblies for such studies requires a suitable way to hold the two components close enough together that they can interact effectively. Commonly, this is to use a bridging ligand in which there is a covalent linkage between the two sites; there are very many such covalently-linked systems, of which the commonest are based on metalloporphyrins or polypyridyl complexes of $d^{6}$ metals [Ru(II), Os(II), $\operatorname{Re}(\mathrm{I})]$ [1, 2, 3, 4, 5]. Alternatively, non-covalent interactions such as hydrogen-bonding or aromatic $\pi$-stacking (or often a combination of several such interactions) can be used to control association of the chromophore and quencher, following the 'supramolecular' methods that are employed in natural photosynthesis [6].

In this article are summarised the results of our resent work in these areas, using both covalently- and non-covalently linked chromophore/quencher assemblies. It is in two parts: the first concerns covalentlylinked polynuclear complexes based on the binucleating bridging ligand $2,2^{\prime}: 3^{\prime}, 2^{\prime \prime}: 6^{\prime \prime}, 2^{\prime \prime \prime}$-quaterpyridine; the second concerns the synthesis of chromophoric metal complexes with pendant hydrogen-bonding substituents, and the study of inter-component processes across hydrogen-bonded bridges in solution.

\section{RESULTS}

2.1. Covalently-linked chromophores: complexes of $2,2^{\prime}: 3^{\prime}, 2^{\prime \prime}: 6^{\prime \prime}, 2^{\prime \prime \prime}$-quaterpyridine (AB)

Ligand synthesis and structure. There are many bridging ligands known which contain two 2,2' bipyridyl (bipy) units linked by a covalent bridge [5, 7]. Of these the simplest is $2,2^{\prime}: 4^{\prime}, 4^{\prime \prime}: 2^{\prime \prime}, 2^{\prime \prime \prime}$ quaterpyridine, in which the two bipy units are linked 'back-to-back' (Scheme 1) [7]. However the

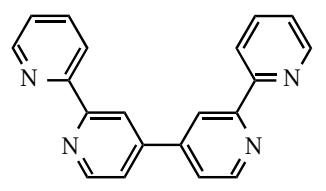

$2,2^{\prime}: 4^{\prime}, 4^{\prime \prime}: 2^{\prime \prime}, 2^{\prime \prime \prime}$-quaterpyridine

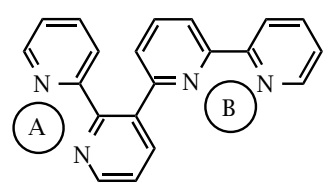

$2,2^{\prime \prime \prime} 3^{\prime}, 2^{\prime \prime}: 6^{\prime \prime}, 2^{\prime \prime \prime}$-quaterpyridine (AB)

Scheme 1. Symmetric and non-symmetric bis-bipyridine chelates: (a) $2,2^{\prime}: 4^{\prime}: 4^{\prime \prime}: 2^{\prime \prime}, 2^{\prime \prime \prime}$-quaterpyridine, (b) $2,2^{\prime}$ : $3^{\prime}, 2^{\prime \prime}: 6^{\prime \prime}, 2^{\prime \prime \prime}$-quaterpyridine $(\mathrm{AB})$.

synthesis of this is rather cumbersome, requiring four steps from 2,2'-bipyridine. Seeking to develop 
a one-step synthesis of the ligand we attempted to exploit the known propensity of pyridine radical anions to couple symmetrically as the $\mathrm{C}^{4}$ position. Thus treatment of pyridine with LDA (lithium diisopropylamide) affords $4,4^{\prime}$-dihydro- $4,4^{\prime}$-bipyridine, which is readily oxidised to $4,4^{\prime}$-bipyridine [8]; similarly, coupling of $3,3^{\prime}$-bipyridine in this way affords $3,3^{\prime}: 4^{\prime}, 4^{\prime \prime}$ : $3^{\prime \prime}, 3^{\prime \prime \prime}$-quaterpyridine via symmetrical dimerisation at the $\mathrm{C}^{4}$ position [9]. We reasoned that treatment of 2, $2^{\prime}$-bipyridine with LDA would therefore afford the symmetric $2,2^{\prime}: 4^{\prime}, 4^{\prime \prime}: 2^{\prime \prime}, 2^{\prime \prime \prime}$-quaterpyridine. However we were surprised to find that the quaterpyridine generated from this reaction had 14 inequivalent aromatic protons in its ${ }^{1} \mathrm{H}$ NMR spectrum, indicative of a low-symmetry structure with all protons inequivalent [10]. The structure was eventually established crystallographically as $2,2^{\prime}: 3^{\prime}, 2^{\prime \prime}: 6^{\prime \prime}, 2^{\prime \prime \prime}$-quaterpyridine (hereafter abbreviated AB, Scheme 1); the crystal structure is in Fig. 1 [11].

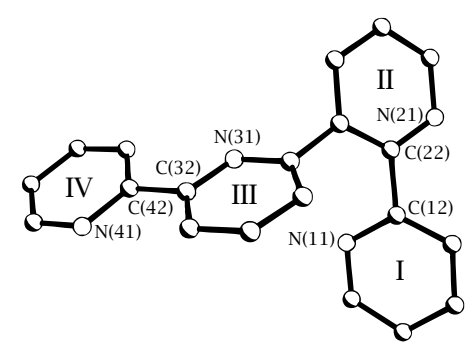

Figure 1. Crystal structure of $\mathrm{Os}-\mathrm{AB}-\mathrm{Ru}$.

Unlike the well-known 'linear' oligopyridines which are more or less planar in the solid state with adjacent pyridyl rings mutually transoid [12, 13], QP is substantially twisted due to the steric crowding around ring II $[\mathrm{N}(21)-\mathrm{C}(26)]$ which is substituted at both $\mathrm{C}^{2}$ and $\mathrm{C}^{3}$. The 'outer' bipyridyl site (rings I and II) has an approximately transoid configuration as expected, but there is an angle of $41.7^{\circ}$ between the mean planes of these two rings. Between rings II and III there is a twist of $66^{\circ}$, which prevents rings II and III from clashing. Finally rings III and IV are more or less trans coplanar $\left(8.9^{\circ}\right.$ between mean planes of these two pyridyl rings) because there is no steric problem to prevent it. Overall, (i) the two 2,2'-bipyridyl fragments are as near transcoplanar as possible given steric limitations, and (ii) the two fragments have a substantial torsion angle between them (about the bond between rings II and III), again for obvious steric reasons. The coupling between the $\mathrm{C}^{3}$ of one bipy unit and the $\mathrm{C}^{2}$ of another has therefore resulted in a structure in which the two bipyridyl binding sites (A and B, Scheme 1) are inequivalent. Site A is relatively unhindered, and can behave like a 'normal' bipy site, whereas site B is significantly sterically hindered because of the bulky substituent attached adjacent to the $\mathrm{N}$ donor atom of ring III.

It seems likely that the unexpected formation of $\mathrm{AB}$ may be ascribed to lithiation of bipy at the $C^{3}$ position of one of the rings (Scheme 2). This metallated lithio-bipyridine would be stabilised by intramolecular chelation from the adjacent pyridine ring, in a manner similar to that which occurs in the ortho-directed lithiation of aromatics bearing electron-rich substituents, such that lithiation of bipy at $\mathrm{C}^{3}$ could occur in preference to reduction to the radical anion. Attack of this lithiated bipy, formally a carbanion with the negative charge at $\mathrm{C}^{3}$, on the $\mathrm{C}=\mathrm{N}$ bond of another bipy equivalent (i.e. at the $\mathrm{C}^{2} / \mathrm{C}^{6}$ position, the normal site of attack for organolithium reagents on pyridines) would give the observed product. Although we have no direct evidence to support this suggestion it is difficult to rationalise the formation of $\mathrm{AB}$ in any other way.

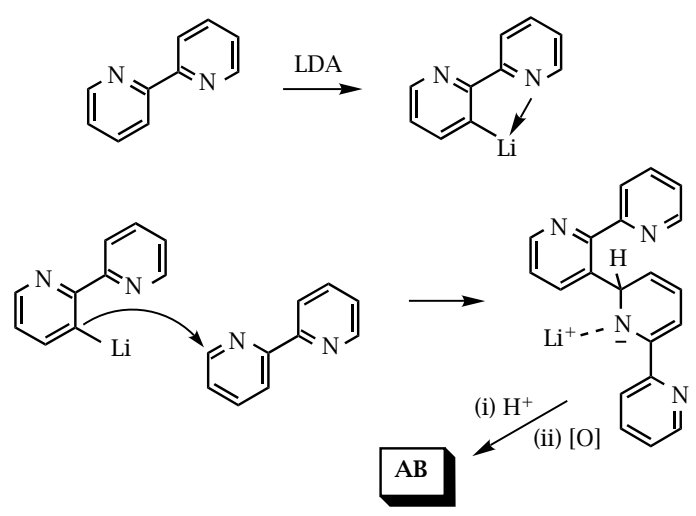

Scheme 2. Possible mechanism for formation of $\mathrm{AB}$ from $2,2^{\prime}$-bipyridine.

Syntheses and structural properties of complexes of $\mathrm{AB}$. The inequivalence of the two coordination sites of $\mathrm{AB}$ could be exploited in preparing metal complexes. Reaction with one equivalent of a metal salt results exclusively in coordination of the metal ion (M) to site A, leaving site B vacant; there is no statistical mixture of free ligand, mononuclear complex, and dinuclear complex which normally occurs with symmetrical ligands. Reaction of this mononuclear complex (denoted $\mathrm{M}-\mathrm{AB}$ ) with a second metal salt $\left(\mathrm{M}^{\prime}\right)$ must then result in coordination at site $\mathrm{B}$, to give $\mathrm{M}-\mathrm{AB}-\mathrm{M}^{\prime}$. Reversal of the sequence of addition of metal ions allows specific preparation of the positional isomer $\mathrm{M}^{\prime}-\mathrm{AB}-\mathrm{M}$, which can have different electrochemical and photophysical properties from $\mathrm{M}-\mathrm{AB}-\mathrm{M}^{\prime}$ because of the inequivalence of the two binding sites.

By exploiting this principle, numerous mononuclear and homo- and hetero-dinuclear complexes have been prepared (see Table 1). Three of them have been structurally characterised: these are $\left[(\text { bipy })_{2} \mathrm{Os}(\mathrm{AB}) \mathrm{Ru}(\text { bipy })_{2}\right]\left[\mathrm{PF}_{6}\right]_{4} \quad$ (abbreviated $\mathrm{Os}-\mathrm{AB}-\mathrm{Ru}) \quad[14], \quad\left[(\mathrm{CO})_{3} \mathrm{ClRe}(\mathrm{AB}) \mathrm{Ru}(\text { bipy })_{2}\right]\left[\mathrm{PF}_{6}\right]_{2}$ (abbreviated $\mathrm{Re}-\mathrm{AB}-\mathrm{Ru}$ ) [15] and $\left[\mathrm{Cl}_{2} \mathrm{Pt}(\mathrm{AB}) \mathrm{Ru}\right.$ (bipy) $\left.{ }_{2}\right]$ $\left[\mathrm{PF}_{6}\right]_{2}$ (abbreviated $\mathrm{Pt}-\mathrm{AB}-\mathrm{Ru}$ ) [16]. The structures of these are in Figs. 2-4 respectively, and a few points are worth particular comment.

Firstly, it is clear that the metal fragment at site A is indeed relatively unhindered in every case and has a normal coordination bipy complexes. In contrast the 
Table 1. Summry of electrochemical and photophysical data fors the complexes

\begin{tabular}{|c|c|c|c|c|c|c|c|c|}
\hline \multirow[t]{2}{*}{ Complex } & \multirow{2}{*}{$\begin{array}{l}\text { Meal-centered re- } \\
\text { dox potential }(V)^{\mathrm{a}}\end{array}$} & \multicolumn{3}{|c|}{ Emission at room temperature } & \multicolumn{2}{|c|}{ Emission at $77 \mathrm{~K}$} & \multirow{2}{*}{$\begin{array}{l}\text { Emission } \\
\text { source }^{i}\end{array}$} & \multirow[t]{2}{*}{ Ref. } \\
\hline & & $\lambda_{\max }(\mathrm{nm})$ & $\tau(\mathrm{ns})$ & $\Phi$ & $\lambda_{\max }(\mathrm{nm})$ & $\tau(\mu \mathrm{s})$ & & \\
\hline $\mathrm{Ru}-\mathrm{AB}$ & +0.90 & $666^{\mathrm{b}}$ & 191 & $1.5 \times 10^{-2}$ & $588^{\mathrm{c}}$ & 5.9 & & 14 \\
\hline $\mathrm{Os}-\mathrm{AB}$ & +0.47 & $792^{\mathrm{b}}$ & 30 & $1.0 \times 10^{-3}$ & $722^{\mathrm{c}}$ & 1.3 & & 14 \\
\hline $\mathrm{Re}-\mathrm{AB}$ & $+0.98^{\mathrm{f}}$ & $626^{\mathrm{d}}$ & 11 & $9.2 \times 10^{-4}$ & $535^{\mathrm{d}}$ & 3.2 & & 15 \\
\hline $\mathrm{Ru}-\mathrm{AB}-\mathrm{Ru}$ & $+0.99,+1.06$ & $674^{\mathrm{b}}$ & 232 & $1.9 \times 10^{-2}$ & $612^{\mathrm{c}}$ & 5.7 & & 14 \\
\hline $\mathrm{Os}-\mathrm{AB}-\mathrm{Os}$ & $+0.56,+0.65$ & $814^{\mathrm{b}}$ & 21 & $8.8 \times 10^{-4}$ & $756^{\mathrm{c}}$ & 1.2 & & 14 \\
\hline $\mathrm{Re}-\mathrm{AB}-\mathrm{Re}$ & $+0.98,+1.10^{\mathrm{f}}$ & $622^{\mathrm{d}}$ & 9 & $5.3 \times 10^{-4}$ & $548^{\mathrm{d}}$ & 2.7 & Re & 15 \\
\hline $\mathrm{Ru}-\mathrm{AB}-\mathrm{Os}$ & $+0.60,+1.05$ & $756^{\mathrm{b}}$ & 41 & $3.2 \times 10^{-3}$ & $716^{\mathrm{c}}$ & 1.5 & Os & 14 \\
\hline $\mathrm{Os}-\mathrm{AB}-\mathrm{Ru}$ & $+0.57,+1.09$ & $808^{\mathrm{b}}$ & 26 & $1.3 \times 10^{-3}$ & $756^{\mathrm{c}}$ & 1.0 & Os & 14 \\
\hline $\mathrm{Ru}-\mathrm{AB}-\mathrm{Re}$ & $+0.93,+1.17^{\mathrm{f}}$ & $644^{\mathrm{d}}$ & 410 & $2.8 \times 10^{-2}$ & $607^{\mathrm{d}}$ & 4.7 & $\mathrm{Ru}$ & 15 \\
\hline $\mathrm{Re}-\mathrm{AB}-\mathrm{Ru}$ & $\cdots+1.04 \cdots f, g$ & $623^{d}$ & 23 & $1.4 \times 10^{-3}$ & $590^{\mathrm{d}}$ & 5.8 & $\begin{array}{l}\mathrm{Re} \text { at } \mathrm{RT} \text {; } \\
\mathrm{Ru} \text { at } 77 \mathrm{~K}\end{array}$ & 15 \\
\hline $\mathrm{Ru}-\mathrm{AB}-\mathrm{Pt}$ & $+0.92^{\mathrm{h}}$ & $640^{\mathrm{b}}$ & 280 & $2.3 \times 10^{-2}$ & $598^{c}$ & 4.8 & & 18 \\
\hline $\mathrm{Pt}-\mathrm{AB}-\mathrm{Ru}$ & $+1.05^{\mathrm{h}}$ & $624^{\mathrm{b}}$ & 13 & $7.5 \times 10^{-4}$ & $586^{\mathrm{c}}$ & 6.0 & & 18 \\
\hline $\mathrm{Ru}-\mathrm{AB}$ & +0.90 & $610^{\mathrm{e}}$ & 320 & $2.8 \times 10^{-2}$ & $602^{\mathrm{e}}$ & 5.2 & & 17 \\
\hline $\mathrm{Ru}-\mathrm{AB}_{2}$ & +0.90 & $612^{\mathrm{e}}$ & 220 & $1.8 \times 10^{-2}$ & $604^{\mathrm{e}}$ & 5.0 & & 17 \\
\hline $\mathrm{Ru}-\mathrm{AB}_{3}$ & +0.90 & $612^{\mathrm{e}}$ & 160 & $1.0 \times 10^{-2}$ & $606^{\mathrm{e}}$ & 4.8 & & 17 \\
\hline $\mathrm{Ru}-\mathrm{AB}-\mathrm{Re}$ & $+0.93,+1.17^{\mathrm{f}}$ & $622^{\mathrm{e}}$ & 1010 & $1.1 \times 10^{-1}$ & $607^{\mathrm{e}}$ & 4.7 & $\mathrm{Ru}$ & 17 \\
\hline $\mathrm{Ru}-(\mathrm{AB}-\mathrm{Re})_{2}$ & $+0.98,+1.17^{\mathrm{f}}$ & $612^{\mathrm{e}}$ & 720 & $9.9 \times 10^{-2}$ & $606^{\mathrm{e}}$ & 4.8 & $\mathrm{Ru}$ & 17 \\
\hline $\mathrm{Ru}-(\mathrm{AB}-\mathrm{Re})_{3}$ & $+1.04,+1.15^{\mathrm{f}}$ & $612^{\mathrm{e}}$ & 490 & $6.0 \times 10^{-2}$ & $606^{\mathrm{e}}$ & 4.9 & $\mathrm{Ru}$ & 17 \\
\hline $\mathrm{Ru}-\mathrm{ABH}^{+}$ & & $638^{\mathrm{b}}$ & 175 & & & & & 23 \\
\hline $\mathrm{Bu}-\mathrm{ABMe}^{+}$ & & $634^{\mathrm{b}}$ & 235 & $1.7 \times 10^{-2}$ & $592^{\mathrm{C}}$ & 6.1 & & 23 \\
\hline $\mathrm{Ru}-\mathrm{A}$ & +0.90 & 626 & 500 & $4.8 \times 10^{-2}$ & & & & 25 \\
\hline Os $-\mathrm{T}$ & +0.47 & 750 & 35 & $2.9 \times 10^{-3}$ & & & & 25 \\
\hline $\mathrm{Re}-\mathrm{T}$ & & 614 & 30 & $3.0 \times 10^{-3}$ & & & & 25 \\
\hline $\mathrm{Ru}-\mathrm{C}$ & +0.90 & 626 & 350 & $3.6 \times 10^{-2}$ & & & & 26 \\
\hline Os $-\mathrm{G}$ & +0.47 & 744 & 44 & $2.9 \times 10^{-3}$ & & & & 26 \\
\hline
\end{tabular}

$a$ Measured in MeCN containing 0.1-0.2 $\mathrm{M} \mathrm{Bu}_{4} \mathrm{NPF}_{6}$ as base electrolyte. Potentials are quoted as $V v s$. internal ferrocene/ferrocenium. All processes are chemically reversible unless otherwise indicated (see notes $f$ and $h$ ). ${ }^{b}$ MeCN Solvent, air-equilibrated. ${ }^{c}$ Butyronitrile solvent. ${ }^{d}$ Mixed DMF $/ \mathrm{CH}_{2} \mathrm{Cl}_{2}$ (9:1) solvent, air equilibrated for room-temperature spectra. ${ }^{e}$ Mixed DMF/ $\mathrm{CH}_{2} \mathrm{Cl}_{2}$ (9:1) solvent, degassed at both room temperature and $77 \mathrm{~K} .{ }^{f}$ Irreversible $\operatorname{Re}(\mathrm{I}) / \operatorname{Re}(\mathrm{II})$ couple. ${ }^{g}$ Two processes [Ru(II)/Ru(III), and $\left.\operatorname{Re}(\mathrm{I}) / \mathrm{Re}(\mathrm{II})\right]$ overlapping. ${ }^{h}$ Irreversible $\mathrm{Ru}(\mathrm{II}) / \mathrm{Ru}(\mathrm{III})$ couple. ${ }^{i}$ In these multi-chromophoric complexes, the site of emission gives the direction of energy-transfer; thus in $\mathrm{Ru}-\mathrm{AB}-\mathrm{Os}$ the Oscentered emission implies $\mathrm{Ru} \rightarrow$ Os energy transfer.

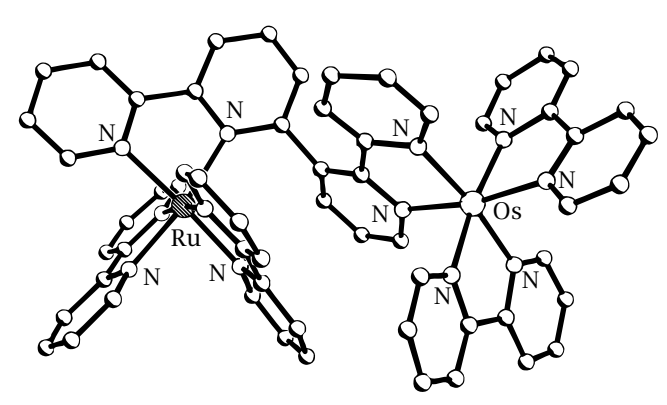

Figure 2. Crystal structure of $\mathrm{Os}-\mathrm{AB}-\mathrm{Ru}$.

metal fragment at site $\mathrm{B}$ in every case is distorted by the sterically bulky substituent adjacent to the $\mathrm{N}$ donor of ring III, and this can be seen specifically in the lengthening of the $\mathrm{M}-\mathrm{N}$ (pyridyl) bond involving ring III of the bridging ligand. For example in $\left[(\mathrm{CO})_{3} \mathrm{ClRe}(\mathrm{AB}) \mathrm{Ru}(\text { bipy })_{2}\right]\left[\mathrm{PF}_{6}\right]_{2}$ the $\mathrm{Ru}-\mathrm{N}(31)$ bond length of 2.135(6) $\AA$ is much longer than the other five $\mathrm{Ru}-\mathrm{N}$ bonds, which are all close to the normal value of $2.056 \AA$ found for $\left[\mathrm{Ru}(\text { bipy })_{3}\right]^{2+}$ [15]. This has significant consequences for the photophysical properties of metal fragments coordinated at site B (see later). Secondly, the bridging ligand has a near-perpendicular twist between the two halves (between rings II and III), which is clearly necessary on steric grounds. Thirdly, only one diastereoisomer was observed in each case despite the presence of two or three chiral centres in the complexes which might have been expected to give a mixture of diastereoisomers. For the structures 


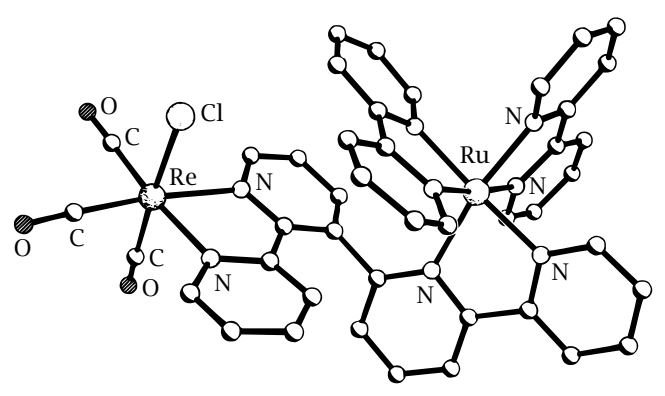

Figure 3. Crystal structure of $\mathrm{Re}-\mathrm{AB}-\mathrm{Ru}$.

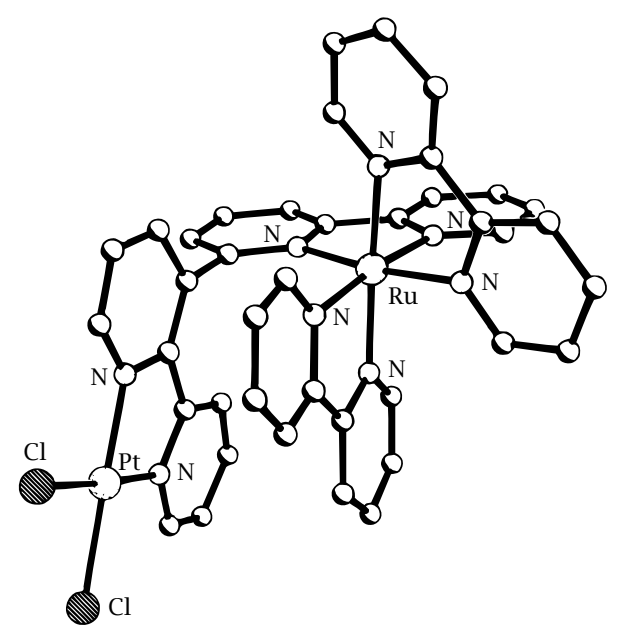

Figure 4. Crystal structure of $\mathrm{Pt}-\mathrm{AB}-\mathrm{Ru}$.

$\mathrm{Os}-\mathrm{AB}-\mathrm{Ru}$ and $\mathrm{Re}-\mathrm{AB}-\mathrm{Ru}$ both metal centres are chiral, and in addition the bridging ligand is chiral by virtue of the twist between the two bipy fragments, so there are three chiral centres; for $\mathrm{Pt}-\mathrm{AB}-\mathrm{Ru}$ there are only two as the four-coordinate Pt fragment is not chiral. However, the chiral centres are not independent of one another. Examination of the structure of $\mathrm{Pt}-\mathrm{AB}-\mathrm{Ru}$ for example (Fig. 4) shows how, given a particular configuration for the $\mathrm{Ru}$ trischelate fragment at site $\mathrm{B}$, one conformation of the bridging ligand results in favourable inter-ligand $\pi$ stacking interactions between $\mathrm{AB}$ and one of the bipy ligands; changing the dihedral angle between the two bipy fragments of $\mathrm{AB}$ by $180^{\circ}$ would remove this stacking. Likewise, in $\mathrm{Os}-\mathrm{AB}-\mathrm{Ru}$ and $\mathrm{Re}-\mathrm{AB}-\mathrm{Ru}$, the configurations of the second and third chiral centres follow from the configuration of the first, for the same reasons: one diastereoisomer appears to be sterically preferred because of favourable interligand $\pi$-stacking interactions. It is of course possible that other diastereoisomers are present in solution and just do not crystallise, but we found no evidence for this during chromatographic purification. These dinuclear complexes may be considered as short fragments of a one-dimensional helical chain, with the helical twist arising from the angular displacement between the two halves of the bridging ligand.
We also prepared the trinuclear complex [(bipy) $\mathrm{Ru}\left\{(\mathrm{AB}) \operatorname{Re}(\mathrm{CO})_{3} \mathrm{Cl}_{2}\right]\left[\mathrm{PF}_{6}\right]_{2}$ and the tetranuclear complex $\left[\mathrm{Ru}\left\{(\mathrm{AB}) \operatorname{Re}(\mathrm{CO})_{3} \mathrm{Cl}\right\}_{3}\right]\left[\mathrm{PF}_{6}\right]_{2} \quad$ [denoted $\mathrm{Ru}-(\mathrm{AB}-\mathrm{Re})_{2}$ and $\mathrm{Ru}-(\mathrm{AB}-\mathrm{Re})_{3}$ respectively; Scheme 3] in which two or three $\left\{\operatorname{Re}(\right.$ bipy $\left.)(\mathrm{CO})_{3} \mathrm{Cl}\right\}$ chromophores are attached to a central $\left\{\mathrm{Ru}(\text { bipy })_{3}\right\}^{2+}$ core [17]. These were prepared from the mononuclear complexes $\left[\mathrm{Ru}\right.$ (bipy) $\left.(\mathrm{AB})_{2}\right]\left[\mathrm{PF}_{6}\right]_{2}$ and $\left[\mathrm{Ru}(\mathrm{AB})_{3}\right]$ $\left[\mathrm{PF}_{6}\right]_{2}$, in which the quaterpyridine $\mathrm{AB}$ is coordinated to the $\mathrm{Ru}$ (II) centre via site $\mathrm{A}$, such that there are two or three pendant sites $\mathrm{B}$ respectively to which the $\left\{\mathrm{Re}(\mathrm{CO})_{3} \mathrm{Cl}\right\}$ groups could be added in a separate step. These are of interest for examination of the 'antenna effect', whereby the excited-state energies of several light-harvesting chromophores are channelled to a single, central quencher group. A calculated structure for the tetranuclear complex $\mathrm{Ru}-(\mathrm{AB}-\mathrm{Re})_{3}$ (based on Molecular Mechanics) shows how the three peripheral $\left\{\mathrm{Re}(\right.$ bipy $\left.)(\mathrm{CO})_{3} \mathrm{Cl}\right\}$ groups completely surround the central $\left\{\mathrm{Ru}(\text { bipy) }\}_{3}\right\}_{2+}$ core (Figure 5).

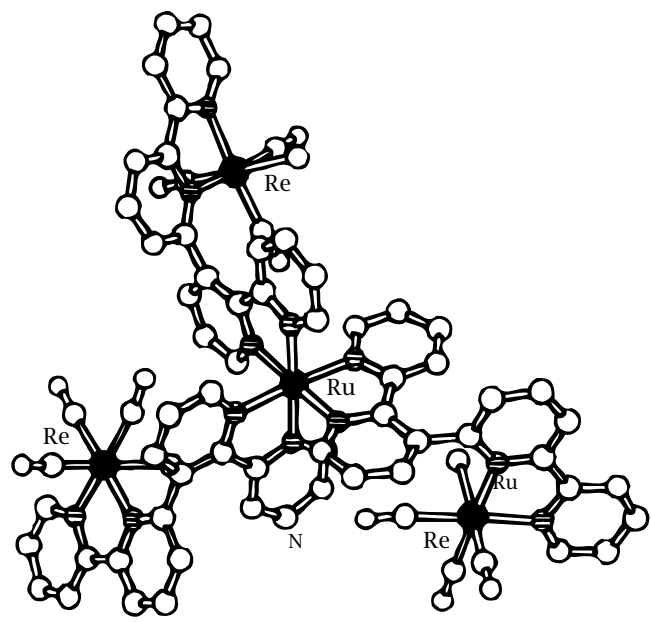

Figure 5. Calculated structure of $\mathrm{Ru}-(\mathrm{AB}-\mathrm{Re})_{3}$.

Electrochemical properties of the complexes of $\mathrm{AB}$. Electrochemical data, based on a combination of cyclic and square-wave voltammetry, is collected in Table 1 . In general the electrochemical processes are readily to assigned as either ligand-based reductions, or as oxidations of the various metal fragments at potentials characteristic of the well-known mononuclear analogues $\left[\mathrm{Ru}(\text { bipy })_{3}\right]^{2+},\left[\mathrm{Os}(\text { bipy })_{3}\right]^{2+}$ and $\left[\operatorname{Re}(\right.$ bipy $\left.)(\mathrm{CO})_{3} \mathrm{Cl}\right]$ (only the metal-based oxidations are included in Table 1). On closer inspection however the effects of the asymmetry of the bridging ligand become apparent, in that the redox potential of a metal fragment coordinated at site $\mathrm{A}$ is different from that of the same metal fragment coordinated at site B. The purest demonstration of this would be to compare, for example, the redox potentials of the two mononuclear complexes $\left[\text { (bipy) }{ }_{2} \mathrm{Ru}(\mathrm{AB})\right]^{2+}$ and $\left[(\mathrm{AB}) \mathrm{Ru}(\text { bipy })_{2}\right]^{2+}$, with the $\mathrm{Ru}(\mathrm{II})$ ion in sites $\mathrm{A}$ and $\mathrm{B}$ respectively. However preparation of $\left[(\mathrm{AB}) \mathrm{Ru}(\text { bipy })_{2}\right]^{2+}$ is not possible, because a single metal ion will always occupy the 

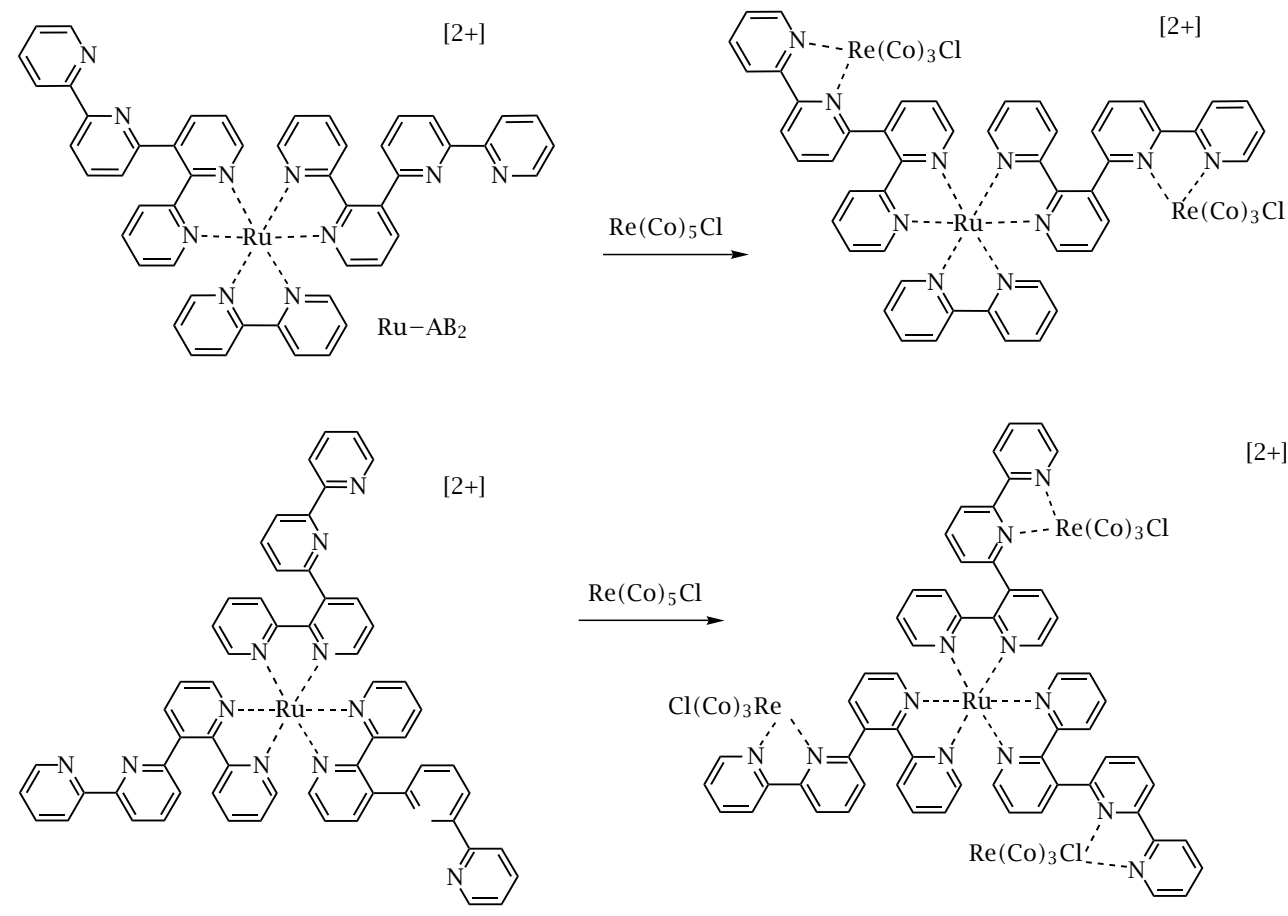

$[2+]$

Scheme 3. Syntheses of $\mathrm{Ru}-(\mathrm{AB}-\mathrm{Re})_{2}$ and $\mathrm{Ru}-(\mathrm{AB}-\mathrm{Re})_{3}$.

less hindered site A first. The next best demonstration therefore is to compare isomeric pairs of dinuclear complexes, in which we can assume that any other effects which will affect the redox potentials (such as metal-metal electronic interactions) are about the same in both isomers and therefore cancel out.

Thus, the $\mathrm{Ru}(\mathrm{II}) / \mathrm{Ru}(\mathrm{III})$ couple in $\mathrm{Ru}-\mathrm{AB}-\mathrm{Pt}$ is at $+0.92 \mathrm{~V}$ (all potentials are quoted $v s$. the ferrocene/ferrocenium couple in $\mathrm{MeCN}$ ), which shifts to $+1.05 \mathrm{~V}$ in the isomer $\mathrm{Pt}-\mathrm{AB}-\mathrm{Ru}$ [18]. This illustrates the general result that the redox potentials of the metal fragments studied shift to more positive potentials (i.e. the oxidation becomes more difficult) when the metal fragment is moved from site A to site B. When the redox potentials of the two metal fragments are wellseparated this has little effect on the behaviour of the complex. For example in $\mathrm{Ru}-\mathrm{AB}-\mathrm{Os}$ the $\mathrm{Os}(\mathrm{II}) / \mathrm{Os}$ (III) and $\mathrm{Ru}(\mathrm{II}) / \mathrm{Ru}(\mathrm{III})$ couples are at $+0.60 \mathrm{~V}$ and $+1.05 \mathrm{~V}$ respectively, such that the Os(II) centre oxidises much more easily than the $\mathrm{Ru}$ (II) centre. In the positional isomer Os $-\mathrm{AB}-\mathrm{Ru}$ the $\mathrm{Os}(\mathrm{II}) / \mathrm{Os}(\mathrm{III})$ couple shifts to the lower potential of $+0.57 \mathrm{~V}$, in accordance with its move to site $\mathrm{A}$, whereas the $\mathrm{Ru}(\mathrm{II}) / \mathrm{Ru}(\mathrm{III})$ couple shifts to the more positive potential of $+1.09 \mathrm{~V}$, in accordance with its move to site B [14]. The separation between the two couples has therefore increased from $450 \mathrm{mV}$ to $520 \mathrm{mV}$, but the Os(II) site will still be the first to oxidise. Likewise all other relevant features of the complex (e.g. that the Os-based MLCT excited state is lower in energy than the Ru-based MLCT excited state, see later) remain basically the same, because the perturbation arising from the inequivalence of sites $\mathrm{A}$ and $\mathrm{B}$ is much less than the fundamentally large difference be- tween the redox and photophysical properties of $\mathrm{Ru}(\mathrm{II})$ and Os(II).

However in the pair $\mathrm{Ru}-\mathrm{AB}-\mathrm{Re}$ and $\mathrm{Re}-\mathrm{AB}-\mathrm{Ru}$ this effect is more significant, because the redox (and photophysical) properties of the component chromophores are much more similar to one another to start with [15]. Thus in $\mathrm{Ru}-\mathrm{AB}-\mathrm{Re}$ the $\mathrm{Ru}(\mathrm{II}) / \mathrm{Ru}$ (III) couple is $240 \mathrm{mV}$ less positive than the $\operatorname{Re}(\mathrm{I}) / \operatorname{Re}(\mathrm{II})$ couple, such that the $\mathrm{Ru}$ (II) centre will clearly oxidise first. In $\mathrm{Re}-\mathrm{AB}-\mathrm{Ru}$ however the positive shift of the $\mathrm{Ru}(\mathrm{II}) / \mathrm{Ru}$ (III) couple and the negative shift of the $\operatorname{Re}(\mathrm{I}) / \operatorname{Re}(\mathrm{II})$ couple compared to $\mathrm{Ru}-\mathrm{AB}-\mathrm{Re}$ mean that the two processes are indistinguishable by voltammetry because they are essentially coincident. The redox properties of $\mathrm{Ru}-\mathrm{AB}-\mathrm{Re}$ are therefore fundamentally different from those of $\mathrm{Re}-\mathrm{AB}-\mathrm{Ru}$, because the perturbation arising from the inequivalence of sites $A$ and $B$ is comparable to the difference in energies between the redox and photophysical properties of the two sites. This has important consequences for the photophysical properties of this pair of isomers (see later).

In the trinuclear and tetranuclear complexes $\mathrm{Ru}-(\mathrm{AB}-\mathrm{Re})_{2}$ and $\mathrm{Ru}-(\mathrm{AB}-\mathrm{Re})_{3}$, the peripheral $\left\{\operatorname{Re}\right.$ (bipy) $\left.(\mathrm{CO})_{3} \mathrm{Cl}\right\}$ fragments in each complex are essentially equivalent and oxidise simultaneously in each complex, such that e.g. $\mathrm{Ru}-(\mathrm{AB}-\mathrm{Re})_{3}$ shows a one-electron $\mathrm{Ru}(\mathrm{II}) / \mathrm{Ru}(\mathrm{III})$ couple at $+1.04 \mathrm{~V}$, followed by simultaneous oxidation of the three $\operatorname{Re}(\mathrm{I})$ groups at $+1.15 \mathrm{~V}$ [17]. In the series $\mathrm{Ru}-\mathrm{AB}-\mathrm{Re}$, $\mathrm{Ru}-(\mathrm{AB}-\mathrm{Re})_{2}$ and $\mathrm{Ru}-(\mathrm{AB}-\mathrm{Re})_{3}$, the increasing number of $\left\{\operatorname{Re}\right.$ (bipy) $\left.(\mathrm{CO})_{3} \mathrm{Cl}\right\}$ substituents on the $\left\{\mathrm{Ru}(\text { bipy })_{3}\right\}^{2+}$ core cause a steady shift in the $\mathrm{Ru}(\mathrm{II}) / \mathrm{Ru}(\mathrm{III})$ redox potential $(+0.93,+0.98,+1.04 \mathrm{~V}$ 
respectively), indicating that each $\left\{\operatorname{Re}(\right.$ bipy $\left.)(\mathrm{CO})_{3} \mathrm{Cl}\right\}$ substituent is weakly electron-withdrawing with respect to the $\left\{\mathrm{Ru}(\text { bipy })_{3}\right\}^{2+}$ core.

Photophysical properties of the dinuclear $\mathrm{Ru} / \mathrm{Pt}$ and $\mathrm{Ru} / \mathrm{Os}$ complexes. The luminescence emission wavelengths, lifetimes, and quantum yields (at $298 \mathrm{~K}$ and $77 \mathrm{~K}$ ) are collected in Table 1 , together with information on the site of the emission for the heteronuclear complexes and hence the direction of any energy transfer which is occurring. The mononuclear complexes $\mathrm{Ru}-\mathrm{AB}$, Os $-\mathrm{AB}$ and $\mathrm{Re}-\mathrm{AB}$ behave similarly to $\left[\mathrm{Ru} \text { (bipy) }{ }_{3}\right]^{2+},\left[\mathrm{Os}(\text { bipy })_{3}\right]^{2+}$ and $\left[\mathrm{Re}(\right.$ bipy $\left.)(\mathrm{CO})_{3} \mathrm{Cl}\right]$ respectively, showing that site $\mathrm{A}$ of the ligand $\mathrm{AB}$ behaves like a conventional bipy site in so far as the photophysical properties of its metal complexes are concerned.

The first significant point to note is the difference between the Ru-centred emission properties of the isomeric pair $\mathrm{Ru}-\mathrm{AB}-\mathrm{Pt}$ and $\mathrm{Pt}-\mathrm{AB}-\mathrm{Ru}$ [18]. In these complexes the $\left\{\mathrm{PtCl}_{2}\right\}$ fragment is non-luminescent, so any emission will be Ru-based; also we can assume that any inter-component effects (e.g. heavy-atom quenching; electronic inductive effects) will be comparable in the two complexes and so can be ignored in the comparison. Compared to the entirely normal Ru-based emission of $\mathrm{Ru}-\mathrm{AB}-\mathrm{Pt}$, the emission from $\mathrm{Pt}-\mathrm{AB}-\mathrm{Ru}$ is both higher in energy and much weaker (97\% loss of intensity compared to $\mathrm{Ru}-\mathrm{AB}-\mathrm{Pt}$, Table 1 ). The higher energy of the emission (by $400 \mathrm{~cm}^{-1}$ ) is a consequence of the electronic difference between sites A and B which was apparent from the electrochemical data, and in fact the increase in emission energy from the Ru fragment in site B is in accord with its slightly raised redox potential compared to $\mathrm{Ru}-\mathrm{AB}-\mathrm{Pt}$. The substantially weaker emission is ascribable to the inherent steric hindrance at site $\mathrm{B}$ which results in one $\mathrm{Ru}-\mathrm{N}$ bond being unusually long $[\mathrm{Ru}(2)-\mathrm{N}(121)$ is $2.13 \AA$, compared to the other five bonds which lie between 2.05 and $2.08 \AA \AA$ ]. This has the effect of reducing the ligand-field strength at this site, such that the lowest metal-centred (MC) excited state-which is normally well above the emissive ${ }^{3}$ MLCT excited state-is lowered in energy such that it becomes thermally accessible. Since deactivation from the MC state is fast and radiationless, its availability as a consequence of the low ligand-field strength provides an effective quenching pathway. At $77 \mathrm{~K}$ the MC state cannot be thermally populated from the ${ }^{3}$ MLCT state and the emission is restored to its usual intensity.

Both $\mathrm{Ru}-\mathrm{AB}-\mathrm{Os}$ and $\mathrm{Os}-\mathrm{AB}-\mathrm{Ru}$ show only Oscentred emission, whatever the excitation wavelength [14]. That the emission derives from the Os(II) site in each case is obvious from comparison of the emission properties with those of $\left[\mathrm{Os}(\text { bipy })_{3}\right]^{2+}$, whose emission is at much lower energy than that of $\left[\mathrm{Ru}(\text { bipy })_{3}\right]^{2+}$. type chromophores and also has lower intensity and a shorter lifetime. This implies that both complexes show quantitative energy transfer from the $\mathrm{Ru}$ (II) chromophore to the Os(II) chromophore, and this is con- firmed by the observation that the excitation spectrum matches the absorption spectrum in both cases. This is quite predictable behaviour: the MLCT excited-state energy of $\left[\mathrm{Os}(\text { bipy })_{3}\right]^{2+}$ is lower in energy than that of $\left.[\mathrm{Ru} \text { (bipy) }]_{3}\right]^{2+}$, such that the $\mathrm{Ru} \rightarrow$ Os direction for energy transfer is exergonic (by about $3000 \mathrm{~cm}^{-1}$ in these dinuclear complexes). In fact very many dinuclear complexes are known which exhibit $\mathrm{Ru} \rightarrow$ Os photoinduced energy transfer in this way, and such $\mathrm{Ru}$ (II)/Os(II) diads with differing bridging ligands have been used to compare the efficiencies of different linking units to mediate photoinduced energy transfer. In $\mathrm{Ru}-\mathrm{AB}-\mathrm{Os}$ and $\mathrm{Os}-\mathrm{AB}-\mathrm{Ru}$ we can again see the effects of the inequivalence of the two binding sites of the bridging ligand, with the Os-based emission from site B being about $850 \mathrm{~cm}^{-1}$ higher in energy than that from site A. Note that in this case the Os-based emission from site B is not weakened by the steric hindrance of this site; in fact the emission from site $\mathrm{B}$ in $\mathrm{Ru}-\mathrm{AB}-\mathrm{Os}$ is stronger than the emission from site $\mathrm{A}$ in $\mathrm{Os}-\mathrm{AB}-\mathrm{Ru}$. This is because the lower energy of the Os-based ${ }^{3}$ MLCT excited state means that the gap between it and the MC excited state is larger than it is for $\mathrm{Ru}(\mathrm{II})$ chromophores. Thus, lowering the energy of the MC state by weakening the ligand field still does not make it thermally accessible from the ${ }^{3}$ MLCT state, so quenching of the ${ }^{3}$ MLCT state via thermal equilibration with the MC state cannot occur at $298 \mathrm{~K}$.

Photophysical studies (luminescence and timeresolved infra-red) on the dinuclear $\mathrm{Ru} / \mathrm{Re}$ complexes. The pair $\mathrm{Ru}-\mathrm{AB}-\mathrm{Re}$ and $\mathrm{Re}-\mathrm{AB}-\mathrm{Ru}$ show a much more fundamental difference in their photophysical properties than do the two Ru/Os complexes, because (as mentioned earlier) the electronic effects arising from the inequivalence of the two binding sites are now comparable to the inherent differences between the properties of the two chromophores [15]. For $\mathrm{Ru}-\mathrm{AB}-\mathrm{Re}$ the emission (at all excitation wavelengths) is Ru-based, as shown by the characteristically high intensity and long lifetime compared to the emission from Re-based chromophores, and again the excitation spectrum matches the absorption spectrum. Thus, $\mathrm{Re} \rightarrow \mathrm{Ru}$ energy transfer is occurring such that any excitation of the Re chromophore results in energy transfer to, and subsequent emission from, the $\mathrm{Ru}$ chromophore in site A. This is the expected direction of energy-transfer considering the relative ${ }^{3}$ MLCT excited-state energies of the parent $\left[\mathrm{Ru} \text { (bipy) }{ }_{3}\right]^{2+}$ and $\left[\mathrm{Re}\right.$ (bipy) $\left.(\mathrm{CO})_{3} \mathrm{Cl}\right]$ chromophores, and is likely to occur via the Dexter (exchange) mechanism. For $\mathrm{Re}-\mathrm{AB}-\mathrm{Ru}$ in contrast the emission in solution at $298 \mathrm{~K}$ is Re-based at all excitation wavelengths. On changing from $\mathrm{Ru}-\mathrm{AB}-\mathrm{Re}$ to $\mathrm{Re}-\mathrm{AB}-\mathrm{Ru}$, the ${ }^{3} \mathrm{MLCT}$ excited-state energy of the $\mathrm{Ru}$ chromophore will rise and that of the Re chromophore will drop ( $c$. the electrochemical results), such that the lowest excited state is Re-based and $\mathrm{Ru} \rightarrow \mathrm{Re}$ now appears to be the favoured direction for energy transfer.

A study of the excited states of $\mathrm{Ru}-\mathrm{AB}-\mathrm{Re}$ and $\mathrm{Re}-\mathrm{AB}-\mathrm{Ru}$ by picosecond time-resolved infra-red 
(TRIR) spectroscopy provided additional clarification of the energy transfer processes in these two complexes, as this method allows observation and detection of excited states which are not emissive and which therefore cannot be detected by luminescencebased methods [19]. The experiments involved measuring the shift in the carbonyl stretching frequencies of the $\left\{\mathrm{Re}\right.$ (bipy) $\left.(\mathrm{CO})_{3} \mathrm{Cl}\right\}$ chromophore immediately after laser excitation. Formation of the MLCT excited state of $\mathrm{Ru}-\mathrm{AB}-\mathrm{Re}$ results in a shift of all of the CO stretching vibrations to lower energy by $c a .10 \mathrm{~cm}^{-1}$. This implies formation of a Ru-based MLCT excited state in which an electron is promoted from the $\mathrm{Ru}[d(\pi)]$ orbitals onto the bridging $\mathrm{AB}$ ligand. The reduced bridging ligand will in turn make the Re centre more electron-rich, such that back-bonding into the $\pi^{*}$ orbitals of the carbonyl ligands will increase and the $\mathrm{CO}$ bonds will weaken. The TRIR study therefore is exactly in agreement with the luminescence measurements which also showed the emissive excited state to be Ru-based.

For $\mathrm{Re}-\mathrm{AB}-\mathrm{Ru}$ the TRIR spectrum $100 \mathrm{ps}$ after excitation showed a more complicated situation: the CO stretching vibrations of the ground state split into two sets of CO vibrations in the excited state, one slightly lower $\left(c a .10 \mathrm{~cm}^{-1}\right)$ in energy and one much higher ( $c a$. $60 \mathrm{~cm}^{-1}$ ) in energy [19]. This is only consistent with the presence of two excited states, sufficiently similar in energy that both are significantly populated at $298 \mathrm{~K}$, with equilibration between them being slow on the IR timescale. The set of CO vibrations at slightly lower energy than the ground state is consistent with the presence of a Ru-based MLCT excited state, as described earlier. The set of vibrations at much higher energy than the ground state is in contrast consistent with the presence of a Re-based MLCT excited state, in which an electron is promoted from the $\operatorname{Re}(\mathrm{I})$ centre onto the bridging ligand, to give $\mathrm{Re}^{\mathrm{II}}\left(\mathrm{AB}^{\bullet-}\right)$. The back-bonding to the carbonyl $\pi *$ orbitals will be substantially decreased and accordingly their stretching vibrations will become higher in energy.

If both states are populated, as the TRIR results suggest, we need to ask why only emission from the Rebased excited state was observed in the luminescence studies. The answer lies in the intrinsically much faster non-radiative decay of the $\mathrm{Re}^{\mathrm{II}}\left(\mathrm{AB}^{\bullet-}\right)$ excited state. The equilibrium distribution of excited-state populations is therefore pulled in one direction towards that state (Rebased) which deactivates the fastest. This illustrates the power of TRIR spectroscopy as an adjunct to luminescence studies: the luminescence spectroscopy alone could not detect the presence of the populated $\mathrm{Ru}$ based MLCT excited state because it is non-emissive in this situation. It appears that the inherent energy difference between the excited states of $\left[\mathrm{Ru}(\text { bipy })_{3}\right]^{2+}$ and $\left[\mathrm{Re}\right.$ (bipy) $\left.(\mathrm{CO})_{3} \mathrm{Cl}\right]$ is almost exactly compensated for by the inequivalence of the two binding sites of the bridging ligand. The equilibrium between the two excited states can be considered as either an intramolecular energy-transfer between the two MLCT excited states, or (since the bridging ligand is reduced in both cases) as an electron transfer between the two metal centres.

On cooling $\mathrm{Re}-\mathrm{AB}-\mathrm{Ru}$ to $77 \mathrm{~K}$ the emission changes character and becomes Ru-based, as shown by the characteristic vibrational fine structure in the emission spectrum. This is because the Re-based excited state is destabilised more on cooling by the lack of solvent reorganisation than is the Ru-based excited state [20, 21], as shown by a comparison of the mononuclear complexes $\mathrm{Ru}-\mathrm{AB}$ and $\mathrm{Re}-\mathrm{AB}$ : the emission energy of $\mathrm{Ru}-\mathrm{AB}$ increases by $1000 \mathrm{~cm}^{-1}$ on cooling to $77 \mathrm{~K}$, whereas that of $\mathrm{Re}-\mathrm{AB}$ increases by $2700 \mathrm{~cm}^{-1}$. Consequently the Ru-based ${ }^{3}$ MLCT excited state is now the source of the emission and the complex at $77 \mathrm{~K}$ shows normal $\mathrm{Re} \rightarrow \mathrm{Ru}$ energy transfer. The change in the nature of the emission from solely Re-based at $298 \mathrm{~K}$ to solely Rubased at $77 \mathrm{~K}$ is unusual in a di-chromophoric complex, relying as it does on two inequivalent chromophores that are nevertheless very similar in energy. Note that comparison of the Ru-based emission from $\mathrm{RuAB}-\mathrm{Re}$ and $\mathrm{Re}-\mathrm{AB}-\mathrm{Ru}$ at $77 \mathrm{~K}$ shows that the emission is $470 \mathrm{~cm}^{-1}$ higher in energy from site $\mathrm{B}$, in reasonable agreement with the value of $400 \mathrm{~cm}^{-1}$ obtained from comparison of $\mathrm{Ru}-\mathrm{AB}-\mathrm{Pt}$ and $\mathrm{Pt}-\mathrm{AB}-\mathrm{Ru}$ at $298 \mathrm{~K}$ [18].

Photophysical studies on the trinuclear and tetranuclear $\mathrm{Ru} / \mathrm{Re}$ complexes. In the trinuclear complex $\mathrm{Ru}-(\mathrm{AB}-\mathrm{Re})_{2}$ and the tetranuclear complex $\mathrm{Ru}-(\mathrm{AB}-\mathrm{Re})_{3}$, the central $\mathrm{Ru}(\mathrm{II})$ ion is coordinated to site $\mathrm{A}$ of the bridging ligands, and the peripheral Re fragments are all coordinated at site B. On this basis we would expect the Re-based excited state to be higher in energy than the Ru-based one, such that $\mathrm{Re} \rightarrow \mathrm{Ru}$ is the preferred direction of energy transfer and emission will be Ru-based in both complexes. This was found to be the case, with the luminescence from both complexes having all of the characteristic features of Ru-based emission and the $\mathrm{Re} \rightarrow \mathrm{Ru}$ energy-transfer being near100\% efficient [17]. These complexes thus demonstrate the antenna effect, whereby two or more excited states channel their excited-state energy to a single central quenching group, and for $\mathrm{Ru}-(\mathrm{AB}-\mathrm{Re})_{3}$ in particular a substantial proportion of the incident radiation at $\lambda \leq 400 \mathrm{~nm}$ is effectively transferred to the central $\mathrm{Ru}$ group. We note that the energy available from this excited state, about $2.0 \mathrm{eV}$, is considerably higher than in the more common multinuclear complexes where an $\left\{\mathrm{Os}(\text { bipy })_{3}\right\}^{2+}$ group is the energy acceptor (excitedstate energy ca. $1.5 \mathrm{eV}$ ).

We also found that the luminescence behaviour of these complexes was relatively insensitive to the presence of $\mathrm{O}_{2}$. Dissolved $\mathrm{O}_{2}$ is an efficient quencher and normally emission quantum yields and lifetimes are considerably improved by removal of $\mathrm{O}_{2}$ from the solvent; however for the series of complexes $\mathrm{Ru}-\mathrm{AB}$, $\mathrm{Ru}-\mathrm{AB}-\mathrm{Re}, \mathrm{Ru}-(\mathrm{AB}-\mathrm{Re})_{2}$ and $\mathrm{Ru}-(\mathrm{AB}-\mathrm{Re})_{3}$ this effect became steadily less apparent with $\mathrm{Ru}-(\mathrm{AB}-\mathrm{Re})_{3}$ having almost the same emission properties both with 


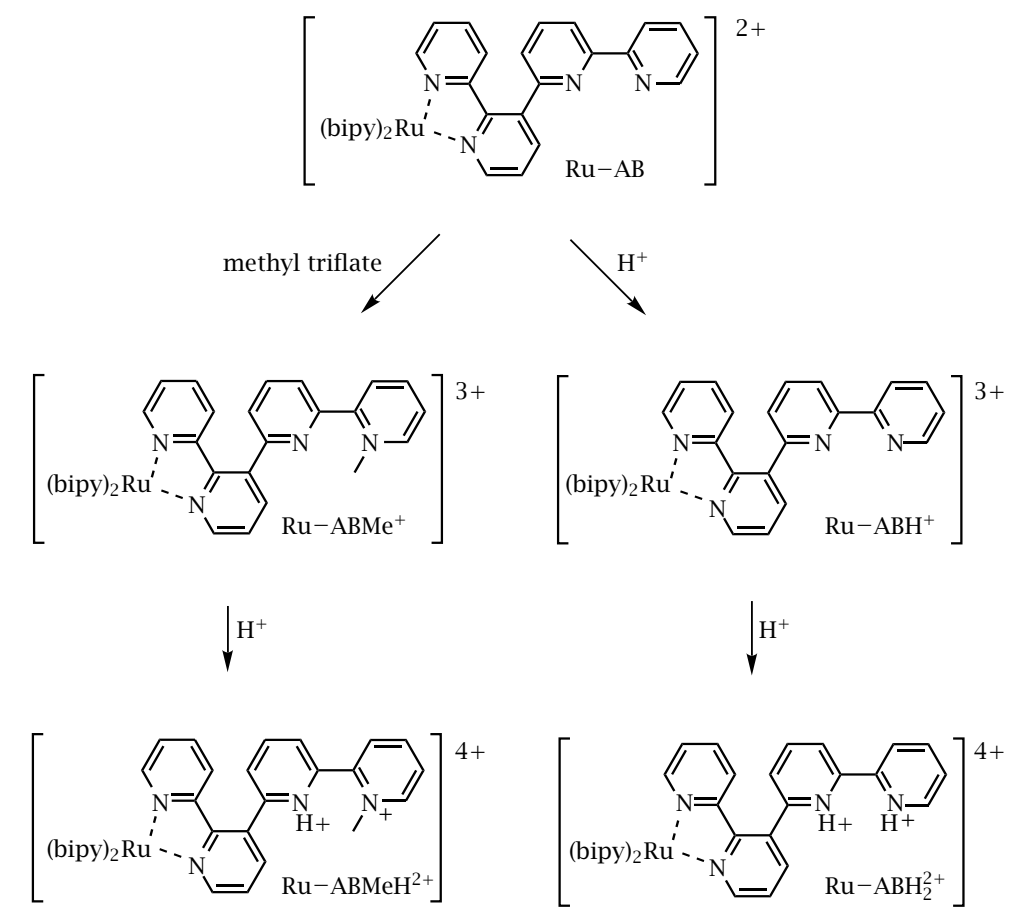

Scheme 4. Methylated and protonated derivatives of $\mathrm{Ru}-\mathrm{AB}$.

and without dissolved $\mathrm{O}_{2}$ present. This is illustrated by the observation that whereas the $\mathrm{O}_{2}$-quenching rate constants for the mononuclear complexes $\mathrm{Ru}-\mathrm{AB}$, $\mathrm{Ru}-\mathrm{AB}_{2}$ and $\mathrm{Ru}-\mathrm{AB}_{3}$ are more or less constant, those for the $\mathrm{Ru} / \mathrm{Re}$ series steadily decrease as the number of peripheral Re groups increases, until for $\mathrm{Ru}-(\mathrm{AB}-\mathrm{Re})_{3}$ the efficiency of $\mathrm{O}_{2}$ quenching of the excited $\mathrm{Ru}$ centre is reduced by about four-fifths compared to the mononuclear complexes [17]. We ascribe this largely to the steric effect arising from the increasing number of bulky $\left\{\operatorname{Re}(\mathrm{CO})_{3} \mathrm{Cl}\right\}$ groups around the central $\mathrm{Ru}$ core [cf. the picture of $\mathrm{Ru}-\mathrm{AB}-\mathrm{Re}_{3}$ in Fig. 5, showing how the Ru core is effectively hidden in the core of the complex], which will prevent $\mathrm{O}_{2}$ from interacting with the Ru centre.

$\mathrm{pH}$-dependence of $\mathrm{Ru}-\mathrm{AB}$ and its $\mathrm{N}$-methylated and reduced forms. The mononuclear complex $\mathrm{Ru}-\mathrm{AB}$, containing as it does a $\left[\mathrm{Ru}(\text { bipy })_{3}\right]^{2+}$ core with a pendant bipy site $[14,15]$, is of interest on its own account for two reasons. Firstly, it is a member of a fairly large group of complexes in which the luminescence of a $\left.[\mathrm{Ru} \text { (bipy) }]_{3}\right]^{2+}$ core may be modulated by protonation or deprotonation of a pendant $\mathrm{pH}$-sensitive functional group [22]. Secondly, methylation of the pendant bipy site to give $\left[(\text { bipy })_{2} \mathrm{Ru}(\mathrm{AB}-\mathrm{Me})\right]\left[\mathrm{PF}_{6}\right]_{3}\left(\mathrm{Ru}-\mathrm{ABMe}^{+}\right.$; Scheme 4) affords a complex containing an electronaccepting, potentially quenching group attached to the $[\mathrm{Ru} \text { (bipy) }]^{2+}$ core [23], and such complexes are of interest for the possibility of generating long-lived charge-separated states following photo-irradiation. Of course, inasmuch as N-protonation may be considered as electronically similar to N-methylation, the two areas are related.
Compared to $\mathrm{Ru}-\mathrm{AB}$, the methylated complex $\mathrm{Ru}-\mathrm{ABMe}^{+}$has a slightly higher luminescence quantum yield and lifetime and a longer emission wavelength [23]. In contrast to other related examples, the methylated pyridine group cannot in this case act as an electron-accepting quencher, as the charge-separated state (oxidised metal and reduced methylated pyridine) that would arise lies above the MLCT state by $0.16 \mathrm{eV}$ and is therefore inaccessible. This may be ascribed to the decoupling of sites A and B arising from the ligand conformation, which prevents the methylated site $B$ from being lowered in energy by extended conjugation with the rest of the complex. Instead the methylated bipy group just acts as an electron-accepting substituent on the $\left[\mathrm{Ru}(\text { bipy })_{3}\right]^{2+}$ core, lowering the energy of the MLCT excited state. This makes the MC excited state (the predominant radiationless decay pathway) less thermally accessible, which accounts for the more intense and longer-lived emission of $\mathrm{Ru}-\mathrm{ABMe}^{+}$ compared to $\mathrm{Ru}-\mathrm{AB}$. However in very acidic conditions, protonation of the remaining pyridyl ring occurs to give $\mathrm{Ru}-\mathrm{ABMeH}^{2+}$ (Scheme 4), in which the doubly charged (protonated and methylated) bipy site B now becomes viologen-like and a much better electron acceptor; consequently the luminescence is quenched. The fact that this requires very acidic conditions, and only starts to be detectable at $\mathrm{pH}<2$, reflects the fact that methylation of site B protects the site from protonation.

The parent complex $\mathrm{Ru}-\mathrm{AB}$ in water/MeCN undergoes protonation at the pendant bipy site with $\mathrm{pK}_{\mathrm{a}}=$ 1.8 , and in its MLCT excited state it has $\mathrm{pK}_{\mathrm{a}}^{*}=2.3$ [23]. The complex is therefore rather poorly basic-pyridine, for example, has a $\mathrm{pK}_{\mathrm{a}}$ of $c a$. 5.3 in water-which may 
be ascribed to the $2+$ charge of the complex which will disfavour protonation. The difference between the $\mathrm{pK}_{\mathrm{a}}$ and $\mathrm{pK}_{\mathrm{a}}^{*}$ values means that formation of the excited state makes the pendant $\mathrm{B}$ bipy sight of $\mathrm{AB}$ slightly easier to protonate, consistent with the fact that ligand $\mathrm{AB}$ bears a negative charge following the MLCT process. The small magnitude of this difference $\left(0.5 \mathrm{pK}_{\mathrm{a}}\right.$ units) is because the substantial twist between the coordinated and pendant halves of $\mathrm{AB}$ largely decouples them, such that the negative charge is largely localised on bipy group A following the MLCT process does not delocalise much onto the pendant site $\mathrm{B}$. This is in obvious contrast to many complexes where the peripheral site of protonation is in the same aromatic ring as that involved in the MLCT process (e.g. protonation of $\mathrm{N}^{4}$ of a coordinated pyrazine ring), where the excited state can be several $\mathrm{pK}_{\mathrm{a}}$ units more basic than the ground state [22]. Like $\mathrm{Ru}-\mathrm{ABMe}^{+}$, the protonated complex $\mathrm{Ru}-\mathrm{ABH}^{+}$is luminescent, and its properties are consistent with the protonated pendant bipy site $B$ acting as an electron-with drawing substituent attached to the $\left[\mathrm{Ru}(\text { bipy })_{3}\right]^{2+}$ core; in this respect protonation has a similar effect to methylation. Also, a second protonation step at $\mathrm{pK}_{\mathrm{a}} \approx 0.5$ occurs ( $c$. protonation of $\mathrm{Ru}-\mathrm{ABMe}^{+}$) to give $\mathrm{Ru}-\mathrm{ABH}_{2}^{2+}$, in which (like $\mathrm{Ru}-\mathrm{ABMeH}^{2+}$ ) site $\mathrm{B}$ is now an effective viologen-like electron acceptor, resulting in luminescence quenching.

$\mathrm{Ru}-\mathrm{AB}$ could be reduced in solution by a solvated electron following pulse radiolysis to give $\left[\mathrm{Ru} \text { (bipy) }{ }_{2}(\mathrm{AB})\right]^{+\bullet}$ (hereafter $\mathrm{Ru}-\mathrm{AB}^{\bullet-}$; the negative charge in this abbreviation denotes that the complex has one units of charge less than $\mathrm{Ru}-\mathrm{AB}$, in the same way as $\left[\mathrm{Ru}(\text { bipy })_{2}(\mathrm{AB}) \mathrm{H}\right]^{3+}$ was denoted $\mathrm{Ru}-\mathrm{ABH}^{+}$); the same reduction could be effected by $\mathrm{CO}_{2}^{--}$[24]. The electronic spectrum of $\mathrm{Ru}-\mathrm{AB}^{\bullet}-$ contains features ascribable to both $\pi \rightarrow$ $\pi^{*}$ transitions within a reduced ligand radical anion, and $\mathrm{Ru}(\mathrm{II}) \rightarrow$ ligand MLCT processes; thus $\mathrm{Ru}-\mathrm{AB}^{\bullet-}$ has undergone ligand-centred reduction, just like $\left.[\mathrm{Ru} \text { (bipy) }]_{3}\right]^{\bullet+}$ whose spectrum it strongly resembles. Unlike $\left[\mathrm{Ru}(\text { bipy })_{3}\right]^{\bullet+}$ however the electronic spectrum of $\mathrm{Ru}-\mathrm{AB}^{\bullet-}$ is $\mathrm{pH}$ dependent, because protonation of the $\mathrm{B}$ site occurs to give the reduced, protonated complex $\left[\mathrm{Ru}(\text { bipy })_{2}\left(\mathrm{AB}^{\bullet}\right) \mathrm{H}\right]^{2+}\left(\right.$ hereafter $\left.\mathrm{Ru}-\mathrm{ABH}^{\bullet}\right)$ with $\mathrm{pK}_{\mathrm{a}}=8$.0. The fact that reduced $\mathrm{Ru}-\mathrm{AB}^{\bullet-}$ protonates much more easily than does $\mathrm{Ru}-\mathrm{AB}$ is obviously related to the negative charge on the $A B$ ligand in the reduced complex. These reduced complexes $\mathrm{Ru}-\mathrm{AB}^{\bullet-}$ and $\mathrm{Ru}-\mathrm{ABH}^{\bullet}$ are unstable and decay rapidly with second-order kinetics.

\subsection{Non-covalently-linked chromophores: complexes with hydrogen-bonding substituents}

Syntheses of ligands and complexes. In contrast to the work described above based on covalently-linked chromophores, we decided to investigate an alternative approach in which mononuclear complexes were functionalised at the periphery with hydrogen-bonding units. This would allow two complexes, e.g. a chro- mophore and a quencher, to be assembled into a single unit by spontaneous association in solution of a complementary pair of pendant hydrogen-bonding groups. The most obvious such groups are the nucleotide bases adenine (A), thymine (T), cytosine (C) and guanine $(\mathrm{G})$, for several reasons. Firstly, complementary hydrogen-bond formation to give the WatsonCrick $\mathrm{A} / \mathrm{T}$ and $\mathrm{C} / \mathrm{G}$ base-pairs is very well known, with the $\mathrm{C} / \mathrm{G}$ triple hydrogen-bond in particular being reasonably strong. Secondly, the free bases are easy to functionalise by alkylation, which allows them to be attached to polypyridyl ligands very easily. Thirdly, the components are commercially available and cheap, in obvious contrast to the many more elaborate artificial hydrogen-bond donor/acceptor units that have been developed for molecular recognition and host-guest chemistry. Others have found these nucleotide bases to be suitable for self-assembly of porphyrin units in solution for similar reasons, and hydrogen-bonded interfaces are known to be able to mediate both photoinduced energy- and electron-transfer between chromophore and quencher units [6].

Attachment of the A, T, C and G units to a bipyridyl ligand via a $-\mathrm{CH}_{2}-$ spacer (Scheme 5) is straightforward, using 5-bromomethyl-2,2'-bipyridine as the alkylating agent [25, 26]. The ligands bipy-A, bipy-T and bipy-C could thus be prepared in a one-pot reaction with the preferred regioisomer being obtained in each case (by reaction at $\mathrm{N}^{9}$ for adenine and $\mathrm{N}^{1}$ for thymine and cytosine). Only bipy-G requires a more elaborate preparation: direct reaction of guanine with alkyl halides results in alkylation of one of the nitrogen atoms at the hydrogen-bonding site, so the protected derivative 2-amino-6-chloropurine was used to attach to 5-bromomethyl-2, 2' -bipyridine by alkylation at the desired position $\mathrm{N}^{9}$, after which acid hydrolysis produced bipy-G [26]. Reaction of each of these ligands with $\left[\mathrm{Ru}\right.$ (bipy) $\left.{ }_{2} \mathrm{Cl}_{2}\right]$ or $\left[\mathrm{Os}\right.$ (bipy) $\left.{ }_{2} \mathrm{Cl}_{2}\right]$ as appropriate produced the desired $\left.\{\mathrm{M} \text { (bipy) }\}_{3}\right\}^{2+}$ complexes $(\mathrm{M}=\mathrm{Ru}, \mathrm{Os})$ bearing one pendant nucleobase group for hydrogen-bonding. In order to optimise solubility of the complexes in low-polarity solvents, and thereby maximise hydrogen-bonding, 4, $4^{\prime}-{ }^{t} \mathrm{Bu}_{2}$-bipy was also used as a co-ligand in place of unsubstituted bipy. Electrochemical, spectroscopic and luminescence studies on the complexes show that they retain the basic properties of the $\left\{\mathrm{M}(\text { bipy })_{3}\right\}^{2+}$ cores (Table 1 ), no doubt because the 'insulating' $-\mathrm{CH}_{2}-$ spacer minimises any electronic perturbation of the complex core by the pendant nucleobase.

Structural studies on the complexes. Although our ultimate aim was to achieve assembly of two component parts in solution, crystallographic studies on the individual complexes proved of interest in showing how the nucleobase pendant groups control association in the solid state. The crystal structures of the complexes $\left[\mathrm{Ru}(\text { bipy })_{2}(\right.$ bipy $\left.-\mathrm{A})\right]\left[\mathrm{Ru}(\text { bipy })_{2}(\right.$ bipy $\left.-\mathrm{AH})\right]\left[\mathrm{PF}_{6}\right]_{5},[\mathrm{Ru}$ $\left({ }^{\mathrm{t}} \mathrm{Bu}_{2} \text { bipy }\right)_{2}($ bipy $\left.-\mathrm{A})\right]\left[\mathrm{PF}_{6}\right]_{2},\left[\mathrm{Os}\left({ }^{\mathrm{t}} \mathrm{Bu}{ }_{2} \text { bipy }\right)_{2}(\right.$ bipy $\left.-\mathrm{T})\right]$ 
$\left[\mathrm{PF}_{6}\right]_{2}$ and $\left[\mathrm{Ru}\left({ }^{\mathrm{t}} \mathrm{Bu}_{2} \text { bipy }\right)_{2}(\right.$ bipy $\left.-\mathrm{C})\right]\left[\mathrm{PF}_{6}\right]_{2}$ are in Figs. 6-9 respectively and, apart from the predictable structures of the $\left\{\mathrm{M}(\text { bipy })_{3}\right\}^{2+}$-type cores, show some interesting features $[25,27]$.<smiles>Nc1ccn(Cc2ccc(-c3ccccn3)nc2)c(=O)n1</smiles>

bipy-C

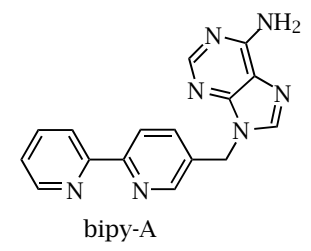

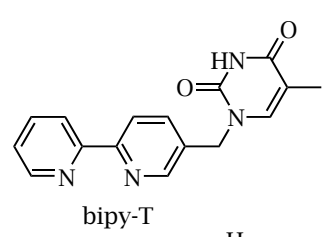

bipy-T<smiles>Nc1nc2c(ncn2Cc2ccc(-c3ccccn3)nc2)c(=O)[nH]1</smiles>

bipy-G<smiles>Nc1ccn(Cc2ccc(-c3ccc(Cn4ccc(N)nc4=O)cn3)nc2)c(=O)n1</smiles><smiles></smiles>

Scheme 5. The nucleobase-substituted bipyridyl derivatives.

In $\left[\mathrm{Ru}(\text { bipy })_{2}\right.$ (bipy-A)] $\left[\mathrm{Ru}\right.$ (bipy) ${ }_{2}$ (bipy-AH) $]\left[\mathrm{PF}_{6}\right]_{5}$ (Fig. 6) there are two crystallographically identical $\left[\mathrm{Ru}\right.$ (bipy) ${ }_{2}$ (bipy-A) $]\left[\mathrm{PF}_{6}\right]_{2}$ complexes in the unit cell related by an inversion centre, and one extra equivalent of $\mathrm{HPF}_{6}$; i.e. one of the two complexes is protonated at the pendant adenine site [25]. Given the symmetry of the unit cell the extra proton (not located crystallographically) must be shared equally (disordered) between the two complexes. The most important feature of this structure is that hydrogen-bonding association between two pendant adenine units occurs across the inversion centre, such that the $-\mathrm{NH}_{2}$ of each interacts with the heterocyclic $\mathrm{N}$ atom of the other to give $\mathrm{N}-\mathrm{H} \cdots \mathrm{N}$ hydrogen-bonds, with an $\mathrm{N} \cdots \mathrm{N}$ separation of $3.05 \AA$. Such self-association of adenine by WatsonCrick type hydrogen bonding is unusual, and may occur because the more normal Hoogsteen-type hydrogenbonding ( $c f$. the crystal structure of 9-methyl-adenine [28]) is prevented by the presence of the extra proton at site $\mathrm{N}^{7}$ on half of the adenine groups. Some support for this view comes form the structure of $\left[\mathrm{Ru}\left({ }^{\mathrm{t}} \mathrm{Bu}_{2} \text { bipy }\right)_{2}\right.$ (bipy-A) $]\left[\mathrm{PF}_{6}\right]_{2}$ (Fig. 7) in which the pattern of intermolecular hydrogen-bonding is completely different from that of the previous complex [25]. Each pendant adenine group is involved in two pairs of hydrogen bonds, to two neighbouring adenine groups, resulting in formation of a hydrogen-bonded ribbon of adenine moieties running through the crystal. The stronger of these hydrogen bonds is between the amino group and the adenine $\mathrm{N}^{3}$ of the adjacent molecule, with the $\mathrm{N} \cdots \mathrm{N}$ separation being $2.94 \AA$. The weaker interaction is between the adenine $\mathrm{N}^{1}$ and one of the hydrogen atoms of the $\mathrm{CH}_{2}$ fragment of an adjacent molecule, with the $\mathrm{N}$. . C separation being $3.52 \AA$. It is interesting that the adenine $\mathrm{N}^{7}$ atom is not involved in hydrogen-bonding, as it is in the structure of 9methyladenine [28]. However it is likely that a dominant controlling feature in the formation of this hydrogenbonding ribbon is the requirement to maximise the separation between the positively charged metal complex units, which explains why the $\{\mathrm{Ru} \text { (bipy) }\}^{2+}$ cores are disposed alternately above and below the ribbon.

The crystal structure of $\left[\mathrm{Os}\left({ }^{\mathrm{t}} \mathrm{Bu}_{2}-\text { bipy }\right)_{2}\right.$ (bipy-T) $]$ $\left[\mathrm{PF}_{6}\right]_{2}$ (Fig. 8) shows that two molecules are associated across an inversion centre via a thymine-thymine double $\mathrm{N}-\mathrm{H} \cdots \mathrm{O}$ hydrogen-bond, whose $\mathrm{N}$. . O separation of $2.94 \AA$ which lies within the normal range

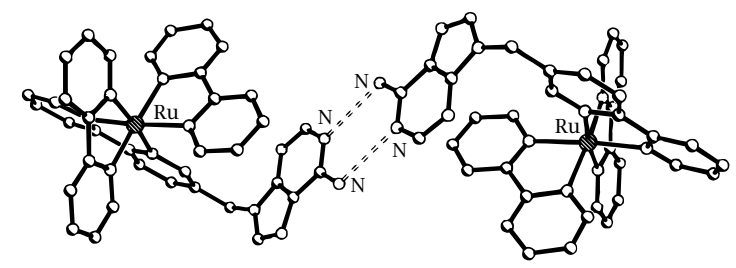

Figure 6. Crystal structure of $\left[\mathrm{Ru}(\mathrm{bipy})_{2}\right.$ (bipy-A) $\left[\mathrm{Ru}(\text { bipy })_{2}\right.$ (bipy- $\left.\left.\mathrm{AH}\right)\right]\left[\mathrm{PF}_{6}\right] 5$, showing the Watson-Crick base-pairing of the adenine units.

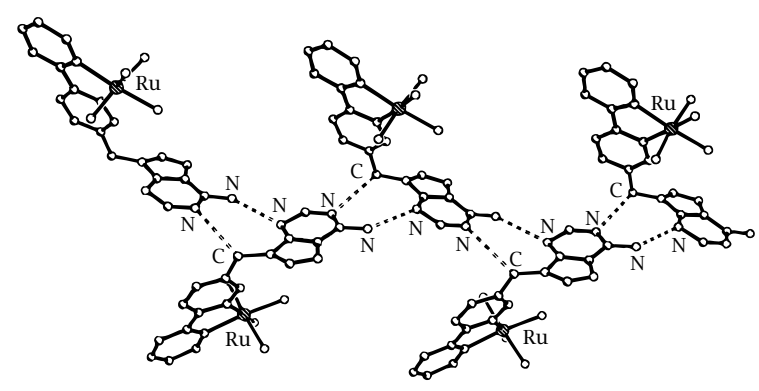

Figure 7. Crystal structure of $\left[\mathrm{Ru}\left({ }^{\mathrm{t}} \mathrm{Bu}_{2} \text { bipy }\right)_{2}\right.$ (bipy-A) $\left[\mathrm{PF}_{6}\right]_{2}$, showing the ribbon formed by Hoogsteen-type as sociation of the adenine units.

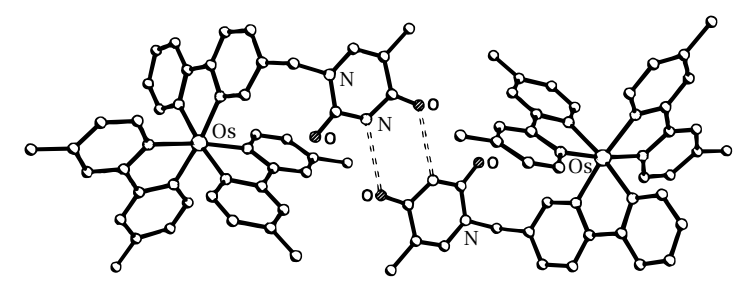

Figure 8. Crystal structure of $\left[\mathrm{Os}\left({ }^{\mathrm{t}} \mathrm{Bu}_{2} \text { bipy }\right)_{2}\right.$ (bipy-T)] $\left[\mathrm{PF}_{6}\right]_{2}$, showing the Watson-Crick base-pairing of the thymine units. The methyle groups of the ${ }^{\mathrm{t}} \mathrm{Bu}$ substituents have been omitted for clarity. 


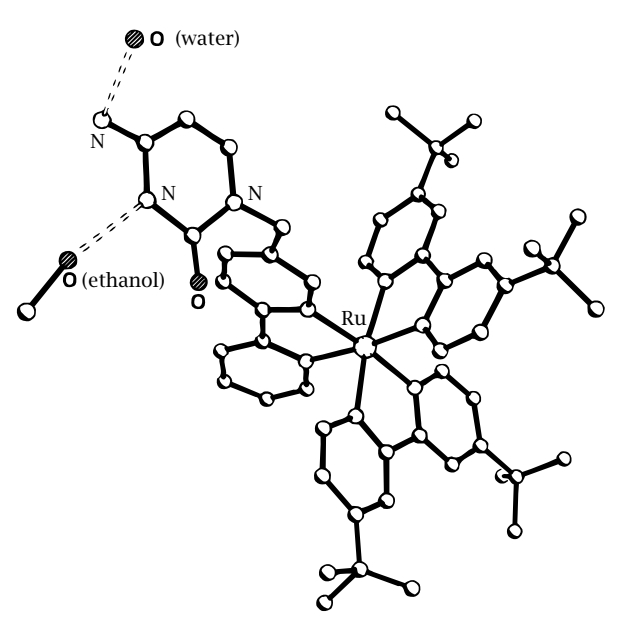

Figure 9. Crystal structure of $\left[\mathrm{Ru}\left({ }^{\mathrm{t}} \mathrm{Bu}_{2} \text { bipy }\right)_{2}\right.$ bipy-C)] $\left[\mathrm{PF}_{6}\right]_{2}$, emphasising association of lattice solvent molecules with the cytosine residue.

for Watson-Crick hydrogen-bonding. This interaction is similar to that observed in the crystal structure of free thymine (as well as other uracil derivatives), in which the intermolecular $\mathrm{N} \cdots$ O distances are 2.81 and $2.84 \AA$ [29]. The slight lengthening of the intermolecular contacts may again be ascribed to electrostatic repulsion between the dicationic complex units.

In contrast to the above three structures, the crystal structure of $\left[\mathrm{Ru}\left({ }^{\mathrm{t}} \mathrm{Bu}_{2}-\text { bipy }\right)_{2}\right.$ (bipy-C) $]\left[\mathrm{PF}_{6}\right]_{2}$ (Fig. 9) shows no self-association between the pendant nucleobase groups, because the cytosine residues are instead involved in hydrogen-bonding interactions with solvent molecules [27]. The heterocyclic $\mathrm{N}$ atom is involved in an $\mathrm{O}-\mathrm{H} \cdots \mathrm{N}$ interaction $(\mathrm{O} \cdots \mathrm{N}$ separation, $2.78 \AA$ ) with an ethanol molecule and the amino group is involved in a hydrogen-bonding interaction with a lattice water molecule $(\mathrm{O} \cdots \mathrm{N}$ separation, $3.08 \AA$ ). This nicely illustrates the importance of conducting hydrogenbonding studies in non-polar solvents, as polar solvents will effectively compete for the hydrogen-bonding sites and prevent the Watson-Crick association in solution.

Solution studies on hydrogen-bonded associates. Initially we studied the pair $\left[\mathrm{Ru}\left({ }^{\mathrm{t}} \mathrm{Bu}_{2}-\text { bipy }\right)_{2}\right.$ (bipy-A) $]$ $\left[\mathrm{PF}_{6}\right]_{2}$ (hereafter $\left.\mathrm{Ru}-\mathrm{A}\right)$ and $\left[\mathrm{Os}\left({ }^{\mathrm{t}} \mathrm{Bu}_{2}-\text { bipy }\right)_{2}(\right.$ bipy $\left.-\mathrm{T})\right]$ $\left[\mathrm{PF}_{6}\right]_{2}(\mathrm{Os}-\mathrm{T})$, which would be expected to associate in solution via a Watson-Crick double hydrogen-bond between the adenine and thymine groups; the neutral complex [Re(bipy-T) $\left.(\mathrm{CO})_{3} \mathrm{Cl}\right](\mathrm{Re}-\mathrm{T})$ was also examined (Table 1) [25]. ${ }^{1} \mathrm{H}$ NMR titration of a fixed amount of $\mathrm{Os}-\mathrm{T}$ by adding aliquots of $\mathrm{Ru}-\mathrm{A}$ showed a steady shift of the thymine $\mathrm{N}-\mathrm{H}$ proton to lower field. This implies that the equilibrium process of equation (1) is fast on the NMR timescale, and standard curve-fitting procedures afforded stability constant values of $c a$. $120 \mathrm{M}^{-1}$ in $\mathrm{CD}_{2} \mathrm{Cl}_{2}$ and $60 \mathrm{M}^{-1}$ in $\mathrm{CD}_{3} \mathrm{CN}$, the lower value being obtained in the more polar (competitive) solvent.

$$
\mathrm{Ru}-\mathrm{A}+\mathrm{Os}-\mathrm{T} \rightleftharpoons \mathrm{Ru}-\mathrm{A}: \mathrm{T}-\mathrm{Os}
$$

Although association is clearly occurring, at the low concentrations (at most $10^{-4} \mathrm{M}$ ) used for solution luminescence studies only $\mathrm{ca}$. $1 \%$ of the complex units will be associated, i.e. the equilibrium of equation (1) lies almost completely to the left and the properties of the associated $\mathrm{Ru}-\mathrm{A}$ : $\mathrm{T}$-Os pair cannot be measured in the presence of such an excess of free monomer units.

In contrast the complementary pair $\left[\mathrm{Ru}\left({ }^{\mathrm{t}} \mathrm{Bu}_{2} \text { bipy }\right)_{2}\right.$ (bipy-C)] $\left[\mathrm{PF}_{6}\right]_{2}(\mathrm{Ru}-\mathrm{C})$ and $\left[\mathrm{Os}\left({ }^{\mathrm{t}} \mathrm{Bu}_{2}-\right.\right.$ bipy) ${ }_{2}$ (bipy-G)] $\left[\mathrm{PF}_{6}\right]_{2}(\mathrm{Os}-\mathrm{G})$ can form a much stronger triple hydrogen-bond, and the extent of association between these two in $\mathrm{CH}-2 \mathrm{Cl}_{2}$ is such that the associated pair $\mathrm{Ru}-\mathrm{C}: \mathrm{G}-\mathrm{Os}$ can be clearly detected in the presence of free monomeric units (equation (2)) [26].

$$
\mathrm{Ru}-\mathrm{C}+\mathrm{Os}-\mathrm{G} \rightleftharpoons \mathrm{Ru}-\mathrm{C}: \mathrm{G}-\mathrm{Os}
$$

The key experiment is simple: the Ru-based luminescence intensity of an equilibrium mixture of $\mathrm{Ru}-\mathrm{C}$ and Os $-\mathrm{G}$ (each at $10^{4} \mathrm{M}$ ) was measured before and after addition of a few drops of ethanol to the $\mathrm{CH}_{2} \mathrm{Cl}_{2}$ solution, and it was found to increase by a factor of 1.4 after the ethanol addition. Since addition of ethanol will break the hydrogen-bonding and drive the equilibrium of equation (2) to the left-hand extreme, it follows that the gain in Ru-based luminescence occurs because all of the $\mathrm{Ru}-\mathrm{C}$ is now free and luminescent, whereas originally some of it was quenched by binding in the $\mathrm{Ru}-\mathrm{C}: \mathrm{G}-\mathrm{Os}$ associate. From this change in emission intensity we can calculate what fraction of the $\mathrm{Ru}-\mathrm{C}$ was hydrogen-bonded at this concentration, and hence determine the association constant which is ca. $5000 \mathrm{M}^{-1}$. Similar results were obtained at several different concentrations of the component parts [26].

Thus, in the $\mathrm{Ru}-\mathrm{C}: \mathrm{G}-\mathrm{Os}$ associate the Ru-based emission is almost completely quenched, and this quenching is removed when the hydrogen-bond is broken. In a control experiment $(\mathrm{Ru}-\mathrm{C}$ with $\left[\mathrm{Os}\left({ }^{\mathrm{t}} \mathrm{Bu}_{2} \text { bipy }\right)_{2}\right.$ (bipy) $]\left[\mathrm{PF}_{6}\right]_{2}$ ), no hydrogen-bonding associate can be formed, and addition of EtOH had no effect on the emission properties of the mixture. Timeresolved measurements showed that whereas the free $\mathrm{Ru}-\mathrm{C}$ had an emission lifetime $\tau$ of 290 ns, the bound $\mathrm{Ru}-\mathrm{C}$ in the $\mathrm{Ru}-\mathrm{C}: \mathrm{G}-\mathrm{Os}$ associate in fact had a residual very weak emission with $\tau=10.5 \mathrm{~ns}$. From these figures the rate constant for energy-transfer across the hydrogen bond could be determined: based on $k_{\text {en }}=$ $1 / \tau_{1}-1 / \tau$, the rate constant for this step is $k_{\mathrm{en}}=$ $9.5 \times 10^{7} \mathrm{~s}^{-1}$ (the average of the values obtained at three different concentrations) over a distance of $c a .13 \AA$ and across a triply hydrogen-bonded interface.

Further work. We are currently extending this work in two directions [30]. Firstly, using these ligands it will be possible to join together other combinations of chromophore and quencher unit in solution. For example, $\mathrm{Rh}$ (III)-polypyridyl complexes can quench Ru-based excited states by electron-transfer [31]. [M(bipy)(cat)] 
$(\mathrm{M}=\mathrm{Pd}, \mathrm{Pt}$; cat $=$ dianion of catechol $)$ complexes act as photosensitisers in their own right and are efficient generators of ${ }^{1} \mathrm{O}_{2}$ following excitation of their LLCT excited states, which could be amenable to sensitisation by a $\left[\mathrm{Ru}(\text { bipy })_{3}\right]^{2+}$-type chromophore [32]. Association of these components in solution using suitablyderivatised bipy ligands will allow the fundamental studies on photoinduced energy- and electron-transfer across hydrogen bonds to be greatly extended.

Secondly, we are examining the possibility of preparing multinuclear assemblies ( $\geq 3$ metal centres) in solution which may demonstrate the antenna effect. These assemblies are based on doubly-substituted ligands such as bipy $-\mathrm{C}_{2}$ and bipy $-\mathrm{G}_{2}$ (Scheme 5); a mixture of (say) $\mathrm{Ru}-\mathrm{C}$ with $\mathrm{Os}-\mathrm{G}_{2}$ could afford some of the trinuclear complex $\mathrm{Ru}-\mathrm{C}: \mathrm{G}-\mathrm{Os}-\mathrm{G}: \mathrm{C}-\mathrm{Ru}$ in solution which is ideally constructed to display the antenna effect, with the Os centre quenching the excited states of both peripheral Ru chromophores via the hydrogenbonded interfaces.

\section{ACKNOWLEDGEMENTS}

It is a pleasure to acknowledge the work of all of my collaborators and the members of my research group who between them have made this work possible. Especially I thank Dr. Francesco Barigelletti of the Istituto FRAE-CNR in Bologna, and his team (Dr. Lucia Flamigni, Dr. Nicola Armaroli, Dr. Massimo Guardigli, Dr. Giuseppe Calogero and Alessandro Gessi) for the photophysical measurements; Prof. Vincenzo Balzani (University of Bologna) for his interest and encouragement during the early stages of this work, and some photophysical measurements with Tiziana Sovrani; Dr. Quinto Mulazzani and Fiorella Casalboni (Istituto FRAECNR, Bologna) for the pulse radiolysis studies; Dr. John Jeffery of the University of Bristol and his team (Dr. David Bardwell, Dr. Karen Mann, Dr. Leigh Rees and Samantha Couchman) for the crystallography; and my own graduate students for all of their excellent synthetic work in the lab (Dr. Rosemary Cleary and Anita Barthram for the quaterpyridine complexes; Dr. Claire White, Monica Fernandez Gonzalez, and Naomi Simpson for the hydrogen-bonding studies). Also I am grateful to the EPSRC (UK) for financial support.

\section{REFERENCES}

[1] V. Balzani and F. Scandola, Supramolecular Photochemistry, Ellis Horwood, Chichester, UK, 1991.

[2] H. Kurreck and M. Huber, Angew. Chem. Int. Ed. Engl. 34 (1995), 849.

[3] M. R. Wasielewski, Chem. Rev. 92 (1992), 435.

[4] J.-P. Sauvage, J.-P. Collin, J.-C. Chambron, S. Guillerez, C. Coudret, V. Balzani, F. Barigelletti, L. De Cola, and L. Flamigni, Chem. Rev. 94 (1994), 993.

[5] V. Balzani, A. Juris, M. Venturi, S. Campagna, and S. Serroni, Chem. Rev. 96 (1996), 759.

[6] M. D. Ward, Chem. Soc. Rev. 26 (1997), 365.
[7] A. J. Downard, G. E. Honey, L. F. Phillips, and P. J. Steel, Inorg. Chem. 30 (1991), 2259.

[8] G. R. Newkome and D. C. Hager, J. Org. Chem. 47 (1982), 599.

[9] T. Kaufmann and R. Otter, Chem. Ber. 116 (1983), 479.

[10] M. D. Ward, J. Chem. Soc., Dalton Trans. (1993), 1321, Note that in this paper the ligand was incorrectly assumed to be $2,2^{\prime}: 4^{\prime}, 2^{\prime \prime}: 6^{\prime \prime}, 2^{\prime \prime \prime}$ quaterpyridine, arising from a $\mathrm{C}^{6} / \mathrm{C}^{4}$ coupling of two bpy radical anions, on the basis of the ${ }^{1} \mathrm{H}$ NMR spectrum (14 inequivalent protons) and the tendency of pyridine [8] and other bipyridines [9] to couple solely at the $\mathrm{C}^{6}$ and $\mathrm{C}^{4}$ positions under the same conditions.

[11] R. L. Cleary, D. A. Bardwell, M. Murray, J. C. Jeffery, and M. D. Ward, J. Chem. Soc. Perkin Trans. 2 (1997), 2179.

[12] E. C. Constable, S. M. Elder, J. V. Walker, P. D. Wood, and D. A. Tocher, J. Chem. Soc., Chem. Commun. (1992), 229.

[13] K. T. Potts, K. A. G. Rayford, and M. Keshavarz-K, J. Am. Chem. Soc. 115 (1993), 2793.

[14] V. Balzani, D. A. Bardwell, F. Barigelletti, R. L. Cleary, M. Guardigli, J. C. Jeffery, T. Sovrani, and M. D. Ward, J. Chem. Soc. Dalton Trans. (1995), 3601.

[15] D. A. Bardwell, F. Barigelletti, R. L. Cleary, L. Flamigni, M. Guardigli, J. C. Jeffery, and M. D. Ward, Inorg. Chem. 34 (1995), 2438.

[16] A. M. Barthram, S. M. Couchman, J. C. Jeffery, and M. D. Ward, unpublished results.

[17] R. L. Cleary, K. J. Byrom, D. A. Bardwell, J. C. Jeffery, M. D. Ward, G. Calogero, N. Armaroli, L. Flamigni, and F. Barigelletti, Inorg. Chem. 36 (1997), 2601.

[18] A. M. Barthram, M. D. Ward, A. Gessi, N. Armaroli, L. Flamigni, and F. Barigelletti, New J. Chem. 22 (1998), 913.

[19] J. R. Schoonover, A. P. Shreve, R. B. Dyer, R. L. Cleary, M. D. Ward, and C. A. Bignozzi, Inorg. Chem. 37 (1998), 2598.

[20] This is because any charge-transfer transition in fluid solution is immediately followed by a compensating reorganisation of the solvent, for two reasons: (i) the altered charge distribution; and (ii) intramolecular structural changes, primarily in the metal-ion first coordination sphere and in the reduced ligand. The first effect (change in charge distribution) is more substantial for a neutral $\left\{\operatorname{Re}(\right.$ bipy $\left.)(\mathrm{CO})_{3} \mathrm{Cl}\right\}$ chromophore than for a dicationic $\left\{\mathrm{Ru}(\mathrm{bipy})_{3}\right\}^{2+}$ chromophore. The second effect (structural reorganisation) is also more significant for the $\left\{\mathrm{Re}(\right.$ bipy $\left.)(\mathrm{CO})_{3} \mathrm{Cl}\right\}$ chromophore because of the substantial variability in Re-C and $\mathrm{C}-\mathrm{O}$ distances arising from the carbonyl ligands; in contrast oxidation of $\mathrm{Ru}(\mathrm{II})$ to $\mathrm{Ru}(\mathrm{III})$ is known to have essentially no effect on the Ru-N(pyridine) bond distances [21]. On immobilisation of the solvent by freezing it, the compensating solvent reor- 
ganisation is prevented and the excited state is accordingly destabilised, but the effect will be more pronounced for the Re-based chromophore .

[21] B. M. Holligan, J. C. Jeffery, M. K. Norgett, E. Schatz, and M. D. Ward, J. Chem. Soc., Dalton Trans. (1992), 3345.

[22] J. G. Vos, Polyhedron 11 (1992), 2285.

[23] M. Guardigli, L. Flamigni, F. Barigelletti, C. S. W. Richards, and M. D. Ward, J. Phys. Chem. 100 (1996), 10620.

[24] F. Casalboni, Q. G. Mulazzani, R. L. Cleary, and M. D. Ward, J. Phys. Chem. (A) 102 (1998), 5749.

[25] C. M. White, M. F. Gonzalez, D. A. Bardwell, L. H. Rees, J. C. Jeffery, M. D. Ward, N. Armaroli, G. Calogero, and F. Barigelletti, J. Chem. Soc., Dalton Trans. (1997), 727.
[26] N. Armaroli, F. Barigelletti, G. Calogero, L. Flamigni, C. M. White, and M. D. Ward, Chem. Commun. (1997), 2181.

[27] C. M. White, K. L. V. Mann, J. C. Jeffery, and M. D. Ward, unpublished results.

[28] T. J. Kistenmacher and M. Rossi, Acta Cryst. B33 (1977), 253.

[29] K. Ozeki, N. Sakabe, and J. Tanaka, Acta Cryst. B25 (1969), 1038.

[30] N. Simpson, C. M. White, F. Barigelletti, and M. D. Ward, unpublished results.

[31] M. T. Indelli, C. A. Bignozzi, A. Harriman, J. R. Schoonover, and F. Scandola, J. Am. Chem. Soc. 116 (1994), 3768.

[32] K. H. Puthraya and T. S. Srivastava, Polyhedron 4 (1985), 1579. 


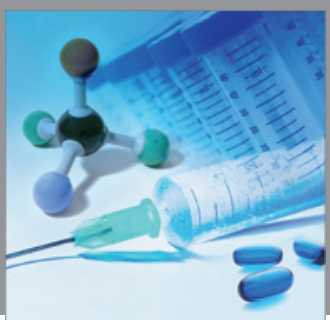

International Journal of

Medicinal Chemistry

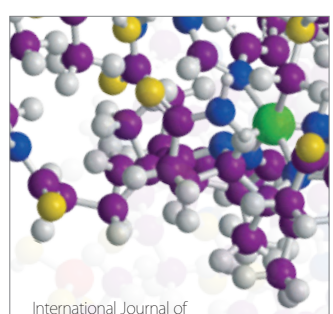

Carbohydrate Chemistry

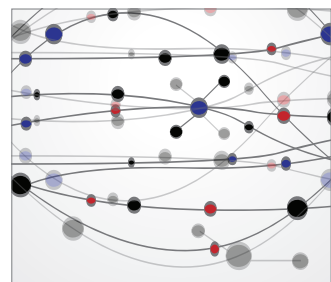

The Scientific World Journal
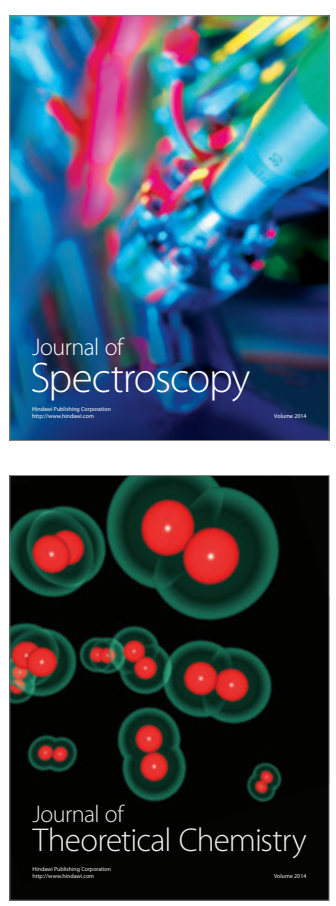
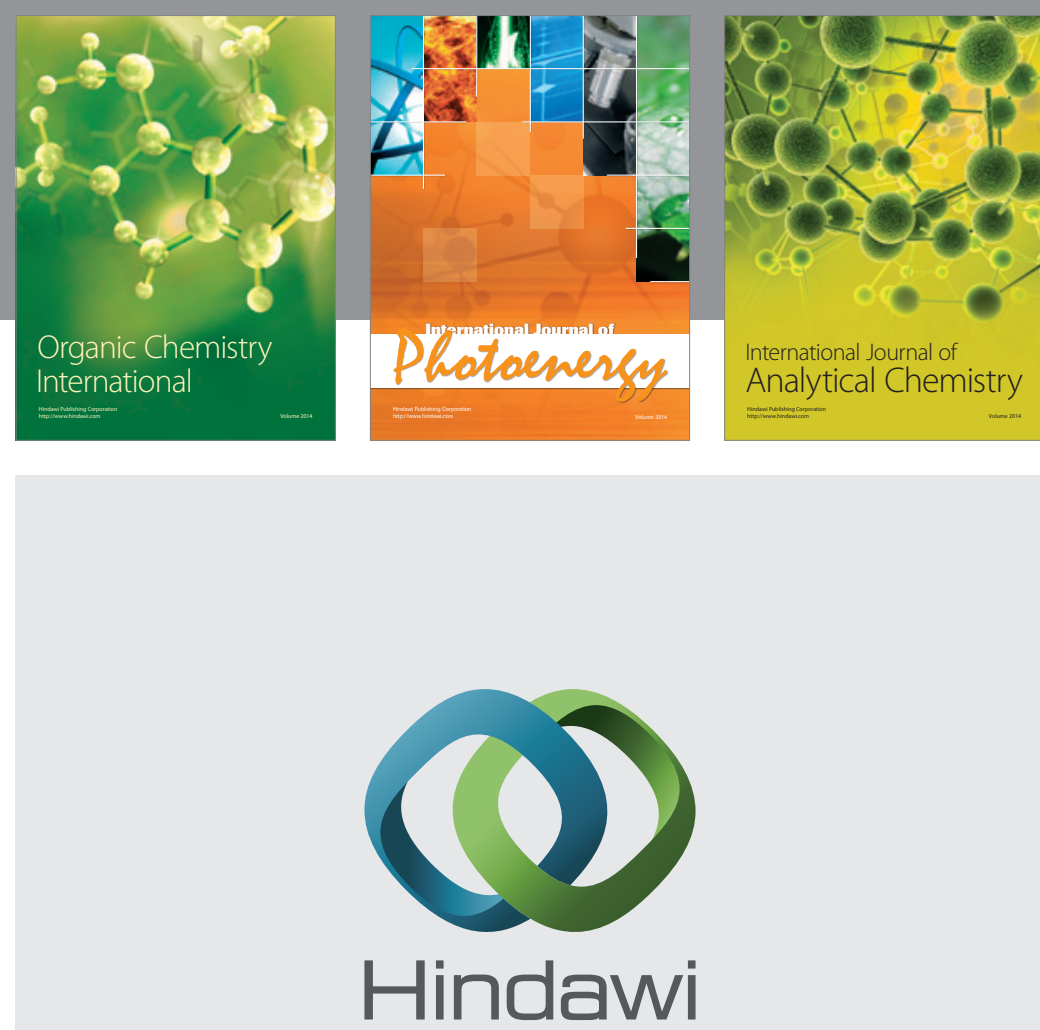

Submit your manuscripts at

http://www.hindawi.com
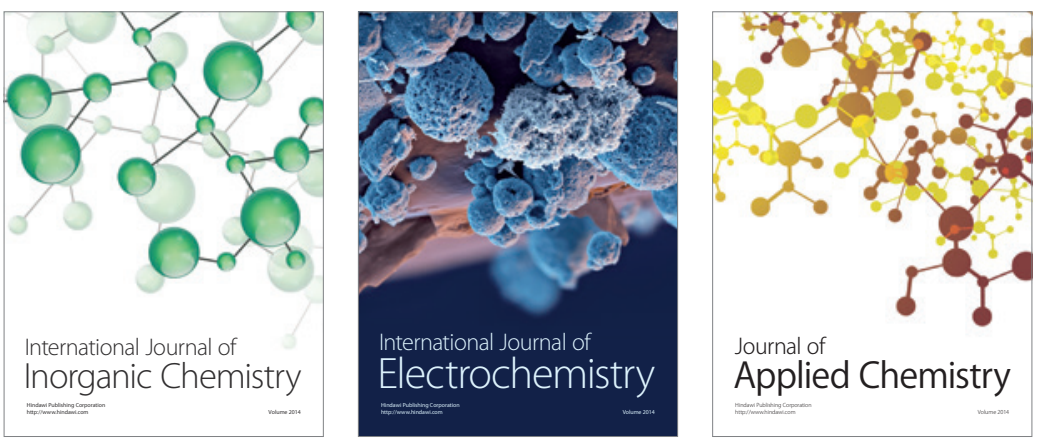

Journal of

Applied Chemistry
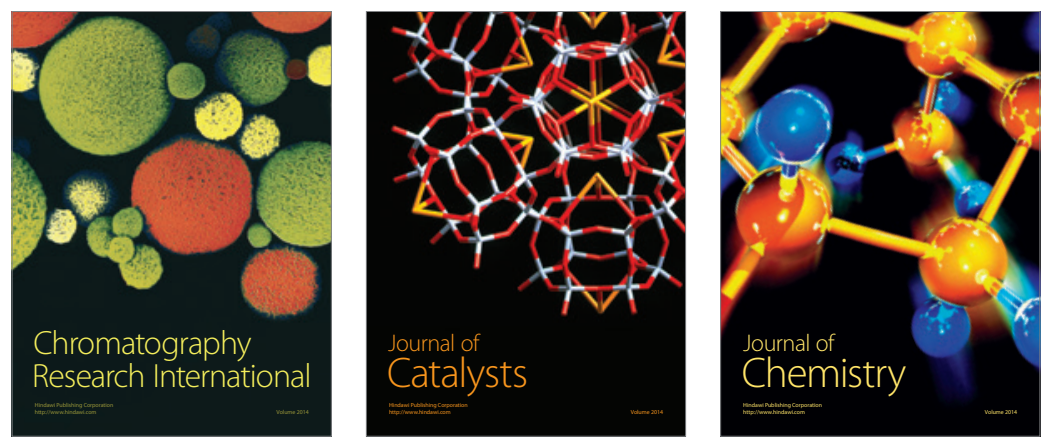
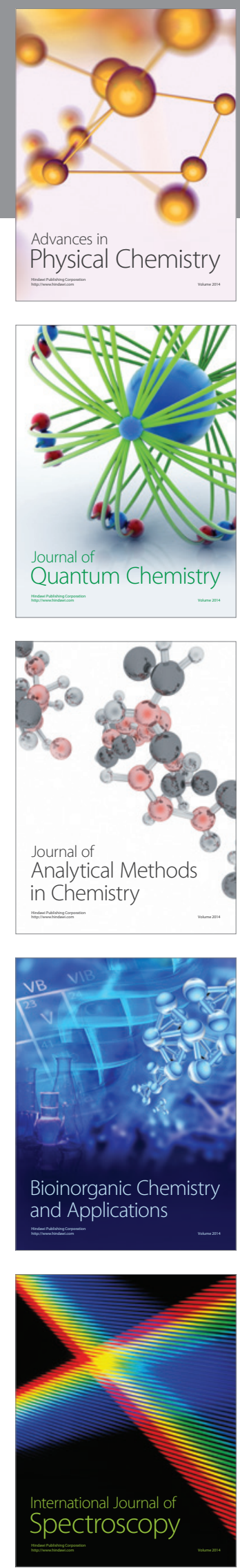